\title{
LA EXCAVACIÓN DE LA CARRETERA DE SAN MARTÍN DE AMPURIAS (GERONA): Un ejemplo de la evolución de los contextos cerámicos durante la Antigüedad Tardía en el litoral catalán
}

\author{
POR
}

\author{
JOAN LLINÀS I POL \\ Centre d'Investigacions Arqueològiques de Girona
}

\section{RESUMEN}

La excavación de urgencia efectuada en 1991 en la carretera de San Martín de Ampurias, a $500 \mathrm{~m}$ al oeste de la ciudad romana de Ampurias y al lado de las iglesias de origen paleocristiano de Santa Madalena y Santa Margarita, proporcionó interesantes hallazgos datables entre los siglos IV y vII d.C. El presente estudio hace hincapié en las notables informaciones que proporciona la gran cantidad de material cerámico de este periodo que se recuperó en el yacimiento.

\section{SUMMARY}

The rescue excavation carried out in 1991 in the road to San Martín de Ampurias, $500 \mathrm{~m}$ West of the Roman city of Ampurias and next to the Paleochristian churches of Santa Madalena and Santa Margarita, revealed interesting findings dated between the IVth - VIIth centuries A.D. The present study focuses on the information provided by the large quantity of pottery from this period that was recovered on the site.

\section{INTRODUCCIÓN}

El estudio de los contextos arqueológicos pertenecientes al periodo histórico que denominamos Baja Antigüedad o Antigüedad Tardía en el noreste de Cataluña era un campo prácticamente inédito hasta hace poco tiempo. Únicamente sobresalían algunos estudios pioneros y aislados referidos a conjuntos muy concretos, como los que proporcionaban la datación de la muralla romana tardía de Gerona (Nolla y Nieto, 1979) o el proceso de despoblamiento de Ampurias (Nieto, 1981). Sólo a principios de la presente década -gracias a los avances en los sistemas de registro y en los estudios ceramológicos, y siguiendo el estilo de las investigaciones del resto de Europa- se han empezado a publicar contextos bien excavados y conocidos procedentes de varias villas de las comarcas gerundenses: Camp de la Gruta (Nolla y Puertas, 1988), Vilauba (Castanyer, Tremoleda y Roura, 1990), Puig Rodon (Nolla y
Casas, 1990), la Font del Vilar (Casas et alii, 1993) o el edificio bajoimperial de Rosas (Nieto, 1993).

En 1991 se realizó una excavación de urgencia en la carretera de San Martín, en la zona suburbana de la antigua Ampurias, en la que colaboraron el Servei d'Arqueologia de la Generalitat de Catalunya, el Museo de Ampurias, la Diputación de Gerona y el Centre d'Investigacions Arqueològiques de Girona. Los trabajos proporcionaron una magnífica estratigrafía y una cantidad ingente de materiales de la etapa histórica que nos interesa, y que constituyen una documentación de primer orden que merece ser publicada con todo detalle. Dado que la investigación posterior a la excavación fue realizada por la totalidad del equipo, debo expresar mi agradecimiento a los compañeros y colegas Xavier Rocas, Susanna Manzano y Anna Maria Puig, ya que, aunque no consten sus firmas, buena parte del presente estudio es también suyo.

El trabajo se divide en dos partes. La primera es una somera descripción de la zona excavada y un estudio detallado de los materiales concretos que permiten establecer unas muy precisas dataciones para las fases tardo-antiguas (fases IVa, IVb, V y VI). Hemos creído necesario incidir en este aspecto, ya que la cantidad ingente de cerámica exhumada nos ha dado la oportunidad - poco frecuente y, por tanto, merecedora de la mayor atención- de disponer de conjuntos ampliamente representativos y muy bien datados.

La segunda parte del artículo, no menos significativa, se centra en las principales líneas de evolución de producciones e importaciones de material cerámico a lo largo del periodo comprendido entre la segunda mitad del siglo iv y el siglo viI. En este sentido, el magnífico ejemplo que constituye nuestro yacimiento permite una extrapolación, sin demasiado riesgo de inexactitudes, a la mayor parte de la zona costera y prelitoral de la antigua Provincia Tarraconense. 


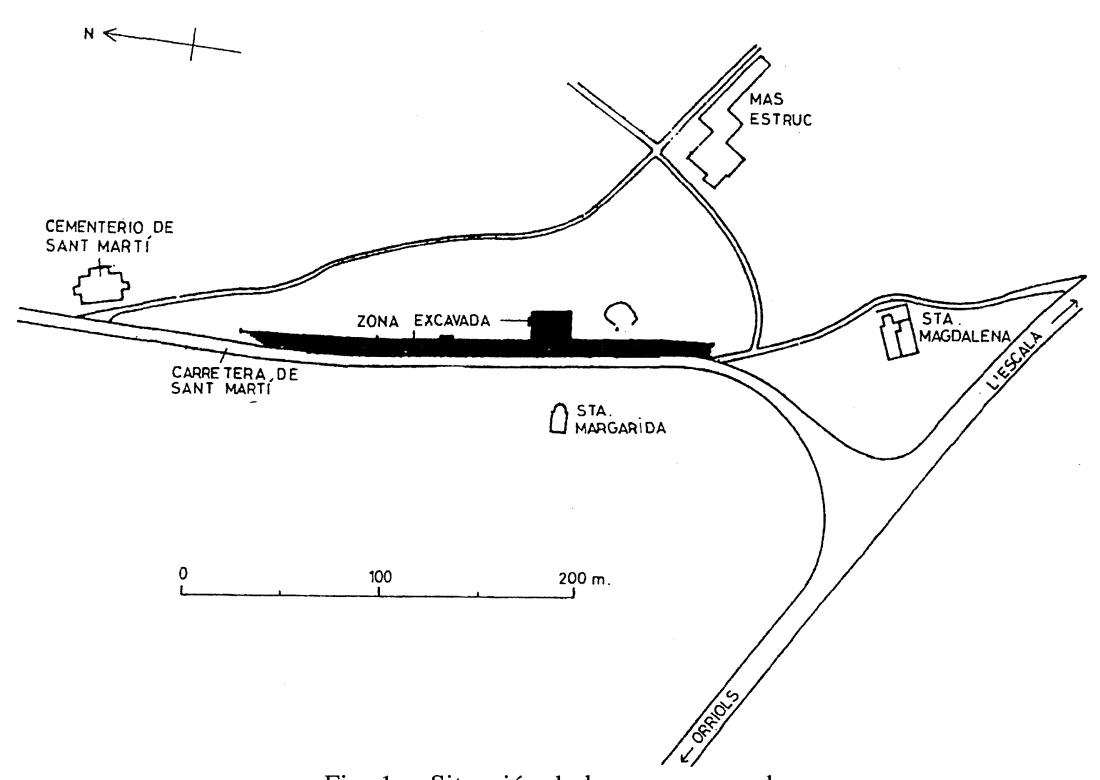

Fig. 1.- Situación de la zona excavada.

\section{LA DATACIÓN DE LAS FASES TARDÍAS}

\section{El yacimiento}

El sector excavado es una larga franja de terreno de $250 \mathrm{~m}$ de longitud por 6' 5 de anchura extendida al lado y a levante de la carretera, desde el cruce de ésta con la carretera de Orriols a l'Escala hasta el actual cementerio de San Martín de Ampurias (fig. 1). Muy cerca se encuentran las iglesias de origen paleocristiano de Santa Margarita y Santa Magdalena y un gran yacimiénto, de momento sin excavar, que según todos los indicios pertenece también a este momento histórico y del que suponemos forman parte nuestros hallazgos (Nolla, 1993: 218220). Asimismo, al lado de la zona excavada en 1991, ya en los años cuarenta y cincuenta se exhumó parte del área cementerial paleocristiana conocida como necrópolis Estruc (Almagro, 1955), de la cual también hallamos algunos vestigios.

\section{Fases previas (I, II y III)}

Se pudieron identificar un total de siete fases, que abarcaban desde época romanorrepublicana hasta el siglo vil d.C. Los vestigios más antiguos de intervención humana corresponden a varios rellenos que tapaban desniveles naturales del terreno (fase I), de los que no se pudo deducir una finalidad más concreta. El material que proporcionaron (Campaniense A y B, Gris de la Costa Catalana, ánforas itálicas...) les otorga una datación de finales del si- glo II a.C.-principios del siglo I a.C., coincidiendo con la fundación de la ciudad romana de Ampurias.

A continuación se identificaron vestigios de una necrópolis de incineración altoimperial (fase II), concretamente dos urnas, una construcción funeraria de planta cuadrangular y varios fragmentos dispersos de ungüentarios y de huesos humanos incinerados (Llinàs et alii, 1992: 358-364). Una de las urnas, de cerámica africana de cocina, se pudo datar hacia finales del siglo I d.C. Se puede suponer con bastante lógica que se trata de una continuación hacia el sudoeste de la necrópolis Torres-Nofre.

En una fase posterior, el tercio central del área excavada se convirtió en un campo de silos (fase III). Se descubrieron un total de 30 , casi todos excavados en la roca, aunque uno de ellos cortaba y deterioraba también estructuras de la fase II (Llinàs et alii, 1992: 360 y 361). La mayor parte de los silos fueron rellenados en el momento de constitución de la fase $\mathrm{V}$, pero algunos presentan inutilizaciones y reaprovechamientos situables en la fase IVa (Llinàs et alii, 1992: lám.6; 375-379). La construcción de estos silos, no fechable per se, se puede situar en un momento inmediatamente anterior al funcionamiento de la necrópolis de inhumación, es decir, a grandes rasgos, en el siglo IV d.C.

\section{Fase IVa}

La zona volverá a convertirse en área cementerial (fase IVa) una vez abandonados (y dejados sin 
rellenar) los silos. El aspecto del nuevo cementerio es el típico de una necrópolis bajoimperial de inhumación, con sepulturas en fosa, estructuras con lecho de tegulae, ánforas, cajas de piedras, dentro de los silos vacíos, y un sepulcro de cámara, todo ello extendido a lo largo de la zona excavada. Esta fase del yacimiento ha sido también ampliamente descrita y estudiada con anterioridad (Llinàs et alii, 1992: 364-380), aunque debemos añadir a los restos funerarios un estrato y un muro relacionado con él y los restos de un nivel de circulación de tierra batida con sus preparaciones. El material proporcionado por estos vestigios se corresponde sin lugar a dudas con el de las sepulturas de la fase IVa, por lo que es lícito suponer que formarían parte de unas estructuras de carácter indeterminado relacionadas con la necrópolis. Las reformas posteriores y el mal estado del yacimiento hacen imposible cualquier tipo de identificación clara.

Para establecer la datación de esta necrópolis debemos tener en cuenta que su funcionamiento tiene lugar en un lapso de tiempo relativamente dilatado, y que cada enterramiento y cada estructura tiene su propia cronología. A pesar de todo, el material arqueológico permite deducir que el momento álgido de funcionamiento de la necrópolis de inhumación se puede situar entre los años 350 y 450, paréntesis cronológico que abarca la totalidad de los materiales datables de la fase IVa, es decir, ánforas y, sobre todo, T.S. Africana D.

Por lo que respecta a la T.S. Africana D, contamos con las siguientes formas, según la clasificación de Hayes (fig. 3, 1-7):

- f. 59 (320-400/420): 3 ejemplares.

-f. 61 (325-450): 3 ejemplares.

-f. 63 (360-440): 1 ejemplar.

-f. 67 (360-470): 1 ejemplar.

-f. 73A (375-475): 1 ejemplar.

-f. 80A (400-500): 1 ejemplar.

-f. 91 (350-650): 2 ejemplares.

- f. 99 (440-650): lejemplar.

- decoración estilo A (iii) (410-470): 1 ejemplar.

Vemos, pues, que de estos 15 ejemplares, 14 se pueden situar entre 410 y 420,13 entre 400 y 420 , y 12 entre 375 y 420 (fig. 2,1), mientras que sólo uno tiene un inicio de producción posterior al año 410. Conjuntos parecidos los podemos hallar por todo el Mediterráneo occidental, pero la cronología laxa de los materiales datables hace que la mayoría de ellos tenga que ubicarse dentro de paréntesis temporales no demasiado precisos.

Con datación a finales del siglo iv o, como mucho, en el cambio de siglo, poseemos la fase de reformas de la factoría de salazones de Rosas, con la formas 58, 59, 61, 67 y 91 (Martín, Nieto y Nolla, 1979: 172-175; Nieto, 1991: 176). En la villa de Puig Rodon (Corçà, Gerona) pertenecen a la fase IV, que los autores sitúan en la primera mitad del siglo $\mathrm{v}$, fragmentos de las formas 59, 61, 64 y 91 A y B (Nolla y Casas, 1990: 203-212). En las excavaciones de la Bourse, en Marsella, el periodo 1, de la primera mitad del siglo $\mathrm{v}$, proporcionó las formas $50,59,61,64,67,68,78,81$ A y B, y 91 A у B (Bonifay, 1983: 308-309). En el horno de T.S. Africana D de El Mahrine (Túnez), tenemos la primera fase, con un repertorio formal casi idéntico al nuestro (f. 59, 61, 63, 67, 73, 76, 91 y decoraciones estilos A (ii) y A (iii)), que el autor data entre finales del siglo IV y mediados del siguiente (Mackensen, 1985: 29-39). Finalmente, en Cartago, en contextos anteriores a la conquista vándala de 439 , se ha hallado un amplísimo repertorio formal en el cual predominan claramente las formas 59, 61, 67, 80/81 y 91, mientras que la 99 es todavía inexistente (Tortorella, 1980).

En los contextos situables en el segundo cuarto del siglo $\mathrm{v}$ siguen predominando todavía las formas 61,80 y 91 , mientras que la 59 experimenta un declive y la 67 se encuentra presente de forma irregular. Cerca del año 440 se empieza a encontrar, todavía de forma minoritaria, un elenco de nuevas formas que acabarán constituyendo la fisonomía de los conjuntos de la segunda mitad del siglo e incluso de más allá del año 500 , como la $87 \mathrm{~A}$ y B, $91 \mathrm{C}$, 94 y 99, entre otras. Ejemplos de esta etapa los encontramos en el vertedero de Vila-Roma, en Tarragona (TED'A, 1989: 123-155), o en las excavaciones de la Schola Praeconum, en el Palatino romano (Whitehouse et alii, 1982: 53-101).

El análisis de las cronologías proporcionadas por la cerámica africana ya permite adivinar, por lo tanto, que esta parte oeste de la necrópolis Estruc funcionaría a un ritmo más intenso durante las últimas décadas del siglo IV y las primeras del v, en un lapso de tiempo aparentemente no demasiado dilatado.

Otros datos cronológicos, proporcionados por las ánforas, están de acuerdo con esta cronología. Hemos podido identificar de manera clara cuatro formas: Keay IV, XXV y LIVB (fig. 3, 20-22), reutilizadas para inhumaciones infantiles, y un borde de Keay XVIII (fig. 3, 19). Las ánforas de forma Keay IV, de procedencia africana y bastante extendidas en los yacimientos catalanes, empiezan a producirse ya alrededor del año 200, pero se llegan a encontrar hasta en contextos de primera mitad del siglo $\mathrm{V}$ (Keay, 1984: 114). También es africana la forma XXV, típica del siglo IV y primera mitad del v (Keay, 1984: 193-198). Teniendo en cuenta que el 


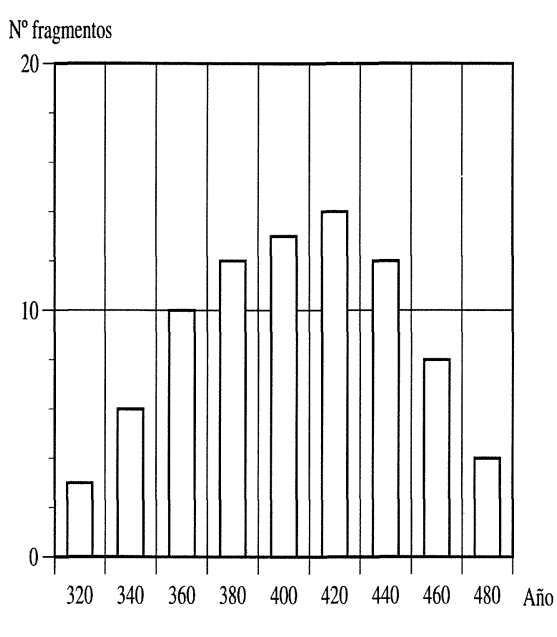

1

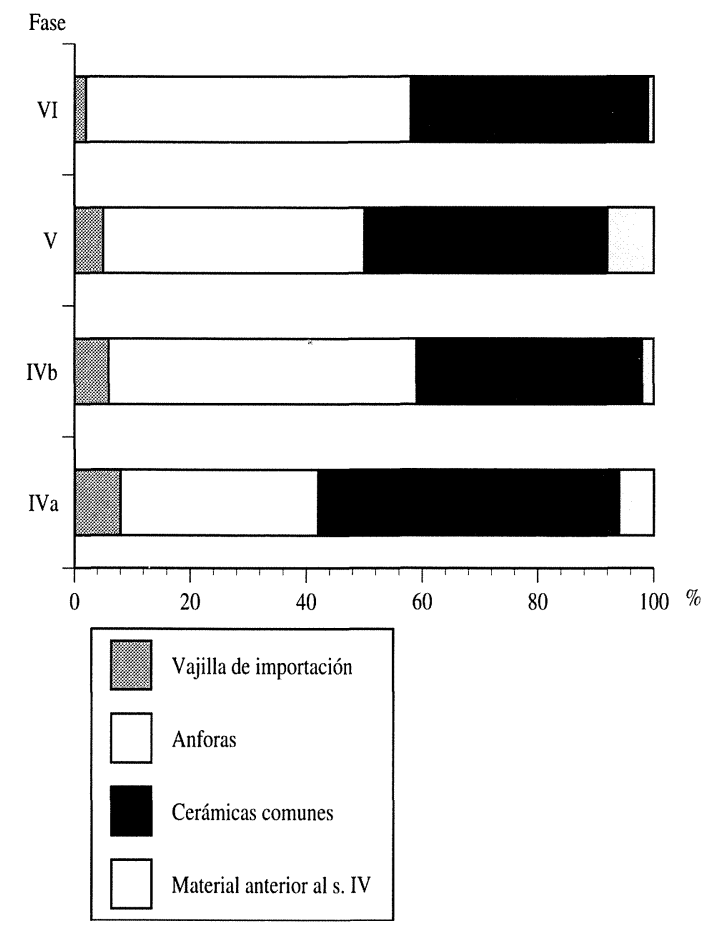

3

Fig. 2.-Gráficas de comparación. 1-Datación de la fase de necrópolis (IVa) a través de las cronologías de T.S. Africana D. 2-Comparación entre T.S. Africana D, T.S. Lucente y T.S. Paleocristiana. 3-Comparación entre los diferentes grupos de materiales. 4-Relación reducida de cocina-común oxidada.
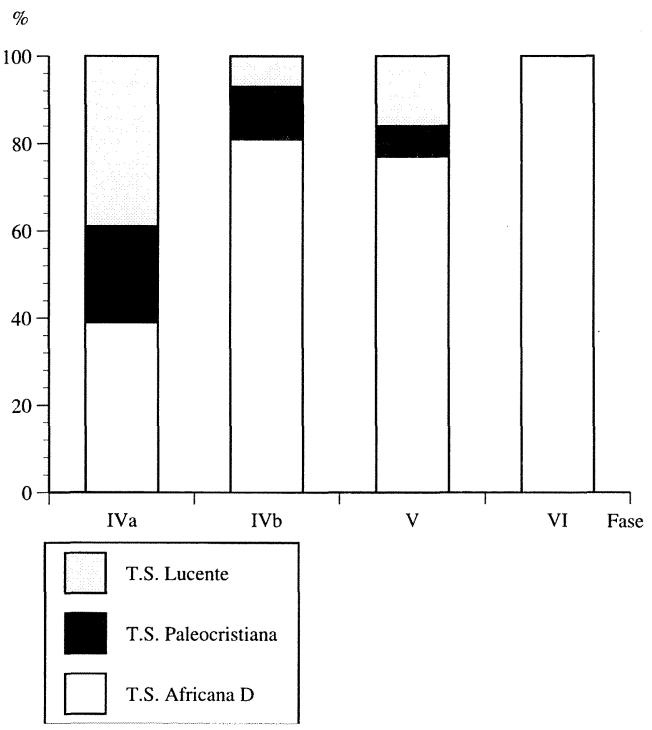

2

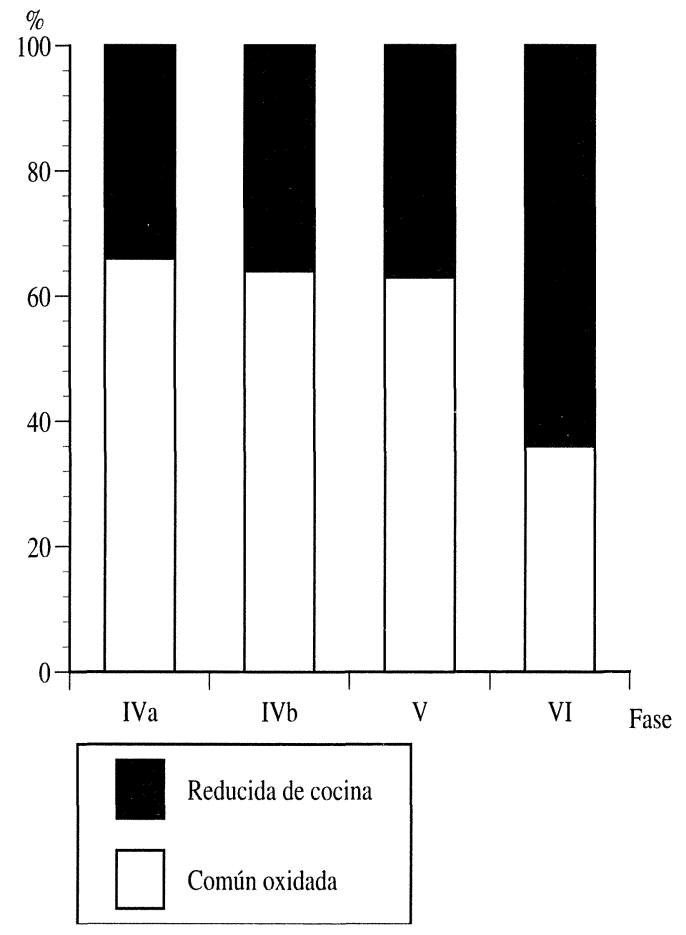

4 Licencia Creative Commons 3.0 España (by-nc) 

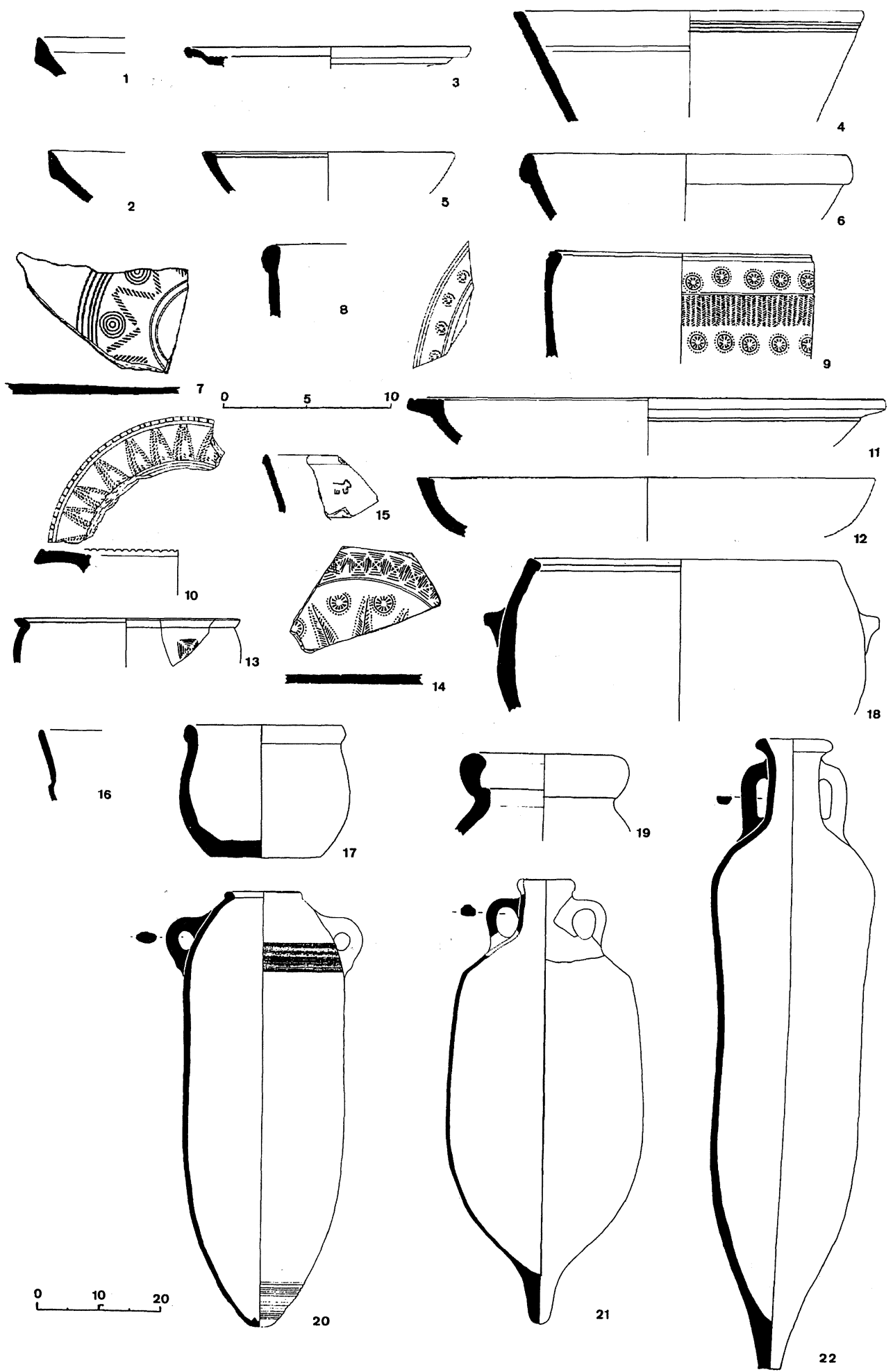

Fig. 3.-Fase IVa. T.S. Africana D: 1 y 2-Hayes 61; 3-Hayes 67; 4-Hayes 80A; 5-variante Hayes 80; 6-Hayes 99; 7-base con decoración A (iii). T.S. Lucente: 8-Lamb. 1/3. T.S. Paleocristiana: 9-Rigoir 15; 10-Rigoir 3; 11-Rigoir 1; 12-Rigoir 4; 13-Rigoir 6; 14-base de plato decorada; 15 y 16-Rigoir 18. 17 y 18-Reducida de cocina. Anforas: 19-Keay XVIII; 20-Keay LIV; 21-Keay IV; 22-Keay XXV. 
resto de los términos post querı de esta fase se ubica dentro de los siglos IV y v de forma clara, parece lógico situar estas dos inhumaciones alrededor de estas fechas. El ánfora bética Keay XVIII, fabricada básicamente en el siglo IV y principios del v, es, en cambio, de un tipo raro en Cataluña (Keay 1984: 156); mientras que la Keay LIV, proveniente de Palestina, es ya muy frecuente en estratos del segundo cuarto del siglo v, como la escombrera de VilaRoma, en Tarragona (Keay 1984: 280-281; TED'A 1989: 284-287)

De hecho, las cuatro formas de ánfora identificadas dan cronologías que pueden extenderse desde principios del siglo III hasta el VI, pero que coinciden en el periodo que va desde finales del siglo IV (fecha más antigua para la Keay LIV) hasta el segundo cuarto del siglo v (fecha más tardía para la Keay IV). Si bien es cierto que no podemos tomar estas dataciones al pie de la letra, no se puede negar que constituyen unas aproximaciones cronológicas coincidentes con la que proporcionan los otros tipos cerámicos de esta fase.

Además, contamos con materiales de importación del sur de la Galia (T.S. Lucente y T.S. Paleocristiana), que no pueden proporcionar dataciones precisas, pero que encontramos en porcentajes muy significativos. La información que estas cerámicas nos proporcionan la analizaremos más adelante.

\section{Fase IVb}

Abandonada la necrópolis, se abre un paréntesis de aproximadamente un siglo de duración por lo que hace referencia a la ocupación humana de la zona. Los únicos signos claros se concretan en el uso puntual de un pequeño sector del yacimiento como vertedero. Ante las evidencias proporcionadas de nuevo por la T.S. Africana D y las ánforas debemos situar la escombrera dentro de un lapso de tiempo que abarcaría desde el año 480 hasta un momento indeterminado de comienzos del siglo vi.

Las formas de T.S. Africana D pertenencientes a esta fase (clasficación Hayes) son las siguientes:

- f. 59 (320-400/420): 2 ejemplares.

- f. 64 (375-450): 1 ejemplar.

-f. 80A (400-500): 2 ejemplares.

- f. 81B (400-500): 1 ejemplar.

- f. 87A (440-500): 11 ejemplares.

- f. 87B (440-525): 10 ejemplares.

- f. 91 indet. (350-650): 3 ejemplares.

- f. 91B (390-530): 3 ejemplares.

- f. 91C (440-600): 2 ejemplares.

- f. 94 (425-600): 2 ejemplares.
- f. 99 (440-650): 26 ejemplares.

- f. Atlante XLVI, 9-10 (400-600): 1 ejemplar.

- decoración estilo A(iii) (410-470): 1 ejemplar.

- estilo E indet. (480-600): 2 ejemplares.

- estilo E (i) (480-540): 1 ejemplar.

Claramente, las formas predominantes son la Hayes 99 (fig. 5, 7-8) y las variantes A y B de la Hayes 87 (fig. 5, 2-3). Juntas suman 47 de los 64 bordes de este tipo cerámico recuperados en la escombrera. Siempre se ha datado la $87 \mathrm{~A}$ en la segunda mitad del siglo $\mathrm{v}$, sin hacerla llegar mucho más allá (Hayes, 1972: 136), datación que, aunque se ha dilatado ligeramente por los dos extremos, ha sufrido pocas modificaciones de importancia. A la 87B, en cambio, se le ha adelantado considerablemente su fecha inicial de c. 500, ya que se ha hallado, aunque de forma minoritaria, en contextos de las décadas centrales del siglo v, como en Cartago antes de la conquista vándala del año 439 (Tortorella, 1980: 136) o en el vertedero de Vila-Roma de Tarragona, alrededor de 440 (TED'A, 1989: 131-132). El momento álgido de las dos variantes de Hayes 87 parece que deberíamos situarlo en las últimas décadas del siglo $\mathrm{v}$.

A su vez, la Hayes 99 presenta un cuadro parecido a la Hayes $87 \mathrm{~B}$ y sus ejemplares más antiguos se puden también llevar al segundo cuarto del siglo v (Atlante, 1981: 259; TED'A, 1989: 139), si bien esta forma tendrá una vida más larga y será una de las de más éxito durante el siglo vi, especialmente la primera mitad, momento en que parece alcanzar su máxima difusión (Atlante, 1981: 109; Reynolds, 1987: 60).

Hay pocos contextos de esta época para realizar comparaciones. Uno de ellos es el relleno de un depósito (U.E. 29) de la factoría de salazones de Rosas. En él, las formas de T.S. Africana D más destacables son: Hayes 61 (3 ejemplares), 87B (3 ejemplares), 91C ( 2 ejemplares), 93 (3 ejemplares), 97 (2 ejemplares) y 99 (5 ejemplares), y también cabe destacar los nueve bordes pertenecientes a diferentes variantes del ánfora Keay LXII. Las formas Hayes 103 y 104 están ausentes. Este relleno se ha datado muy a principios del siglo vi (Nieto, 1993: 103-108).

Un segundo contexto asimilable sería la escombrera excavada en Gardanne (Bouches-du-Roine, Provenza), donde, de 21 ejemplares de T.S. Africana $\mathrm{C}$ tardía y $\mathrm{D}$, siete pertenecen a las variantes $\mathrm{A}$ y $B$ de Hayes 87. También se encuentran representadas las formas $91 \mathrm{C}$ y 93 , con un individuo cada una. El resto de formas catalogadas son, o bien más antiguas, o bien de cronologías inciertas. De nuevo nos encontramos con la ausencia de las formas Ha- 

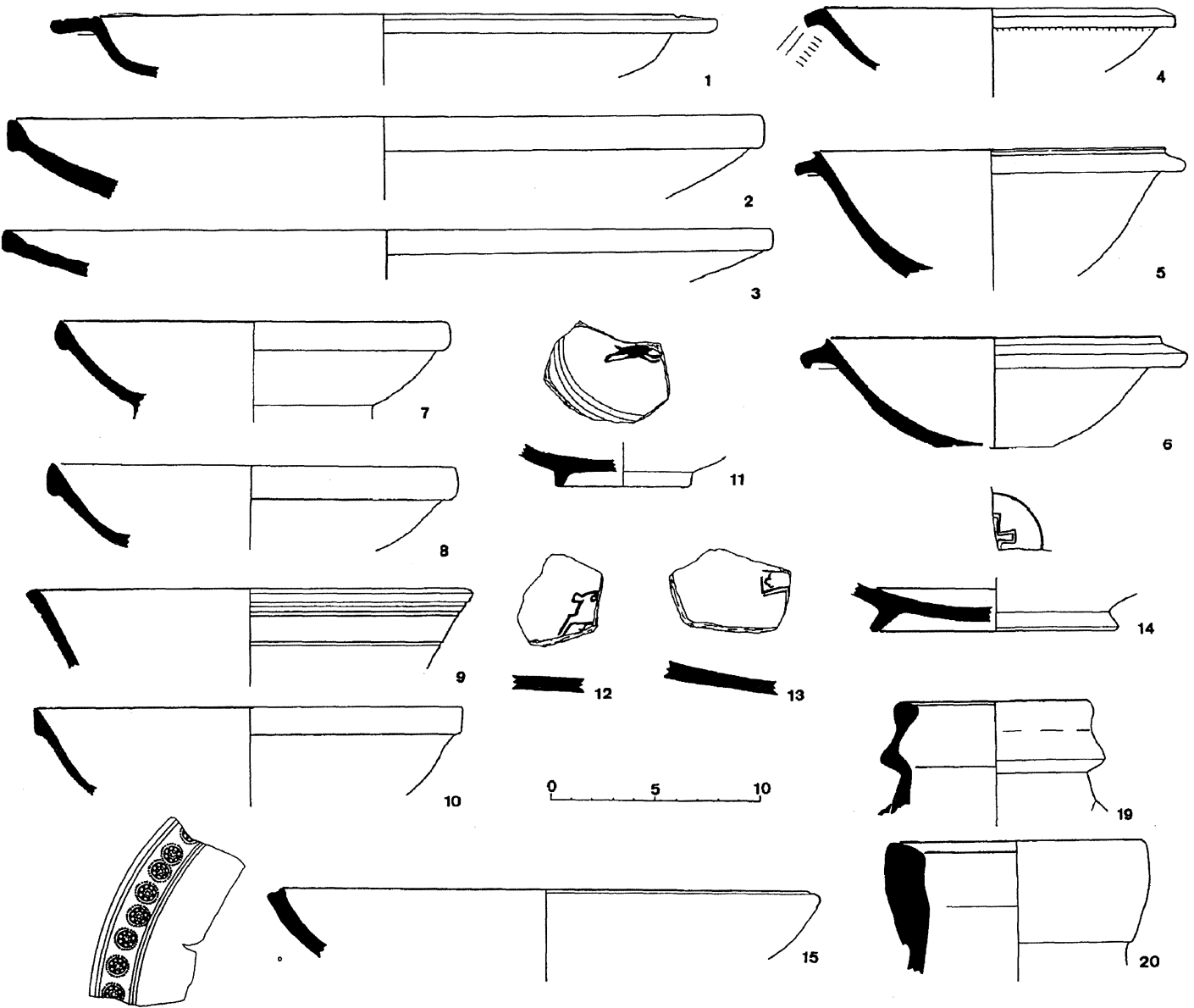

国

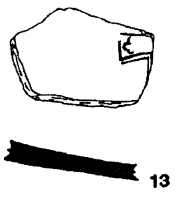

10
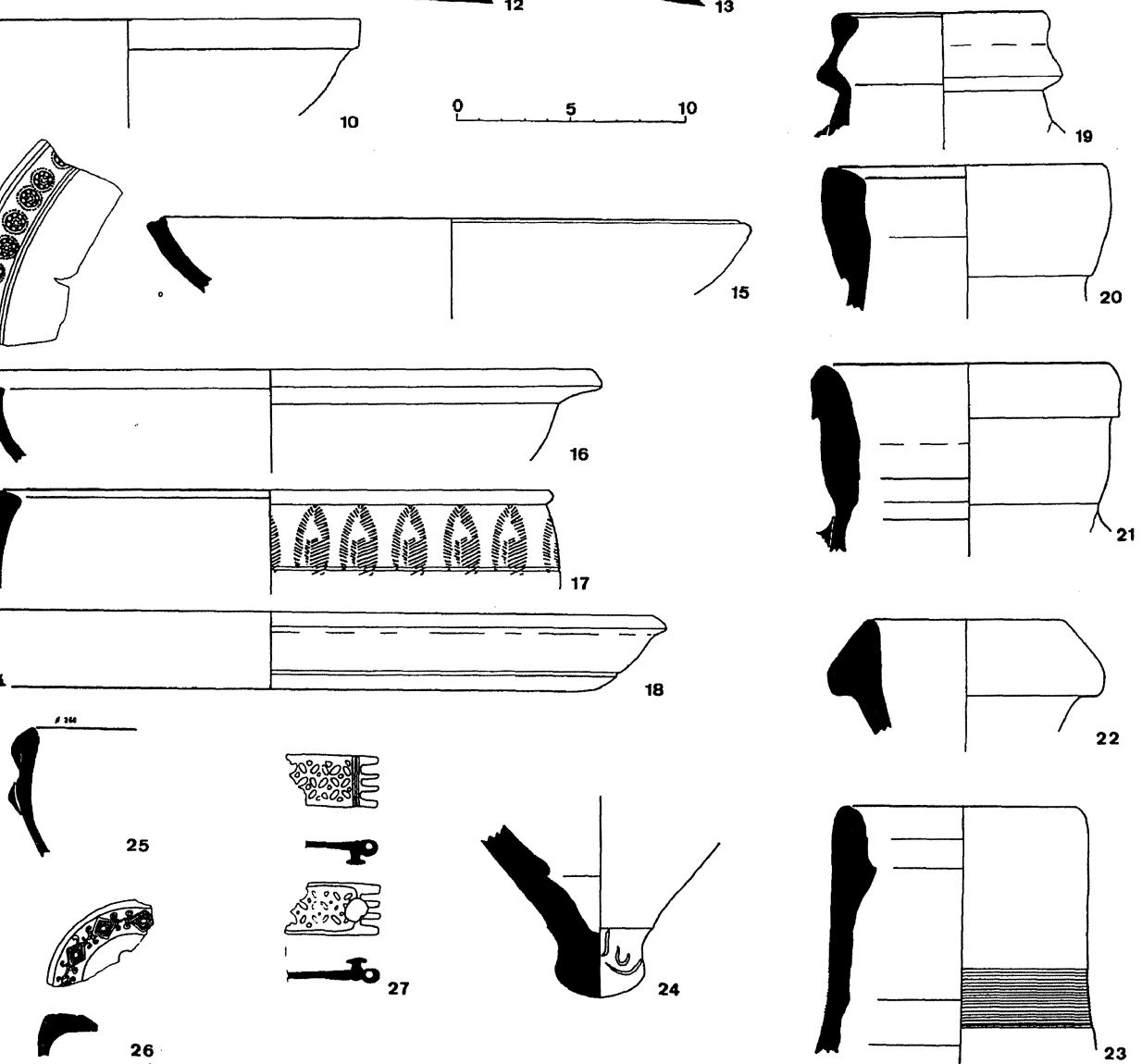

Fig. 4-Fase IVb T. S Africana D: 1-Hayes 59: 2-Hayes 87A: 3-Hayes 87B; 4-Hayes 94; 5 y 6-Hayes $91 \mathrm{C} \cdot 7$ y 8-Hayes 99 9-Hayes 80A; 10-variante Hayes 99 (?); 11-decoración estilo A (iii); 13-decoración estilo E (i); 12 y 14-decoración estilo E indeterminado. T.S. Paleocristiana; 15-Rigoir 4; 16-Rigoir 1; 17-Rigoir 6; 18-Rigoir 8. Ánforas: 19-Keay XIXA; 20-Keay LVIIB; 21-Keay LXIIQ; 22-Keay XIII (?); 23-Keay LV; 24-pivote con graffitti. 25-Reducida de cocina. 26-Lucerna africana. 27-Aplique de bronce. 
yes 103 y 104, aunque debemos tener en cuenta que el conjunto de cerámicas africanas de este vertedero es muy reducido. Los autores datan los materiales exhumados en los primeros decenios del siglo VI (Pelletier et alii, 1991: 338-340).

En las excavaciones de la Bourse, en Marsella, un conjunto asimilable al nuestro es el proporcionado por el periodo $2 \mathrm{~A}$-fase 3 , con una datación de finales del siglo v-inicios del VI (Bonifay, 1983: 314). En él, las formas predominantes son: $91 \mathrm{C}$ (6 ejemplares), $91 \mathrm{~A} / \mathrm{B}$ y 87B (5 ejemplares), y 99 y 94 (4 ejemplares). Cabe destacar, además, la presencia de formas típicas de la producción $\mathrm{C}$ tardía $(82,84,85)$, y de la 104A, inexistentes en nuestro conjunto, así como la falta de las formas $93 \mathrm{y}$, de nuevo, 103.

Es también destacable el material aparecido en las excavaciones de la Antigua Audiencia, en Tarragona, que ofrece un conjunto datable en una fase inmediatamente anterior a la de nuestra escombrera. Se pudo identificar dos momentos (amortización de estructuras imperiales y escombrera), situables en la segunda mitad del siglo $\mathrm{V}$ y separados por un lapso cronológico muy corto (Aquilué, 1993: 125-127 y 144-150). Se puede apreciar la pervivencia de algunas formas que ya aparecían en contextos de la primera mitad de esta centuria (Hayes 67, 80, 91 A/B), el predominio de la Hayes 87, sobre todo la variante A, y la presencia aún escasa de Hayes $91 \mathrm{C}$ y 99 , bastante más abundante en nuestra fase IVb.

Así, aunque somos conscientes del factor azar -posible responsable de la ausencia de la forma Hayes 93 , presente ya en la segunda mitad del siglo $\mathrm{V}$ en su variante $\mathrm{A}-$, es importante destacar la inexistencia en nuestra escombrera de las formas Hayes 103, comenzada a producir alrededor del año 500, y Hayes 104, presente ya en el siglo v, pero que tiene su mayor expansión en la primera mitad del vi (Atlante, 1981: 94-95, 98-99 y 259). En este sentido, debemos hacer notar que, como en nuestro caso, las formas 103 y 104A están ausentes en la U.E. 27 de la factoría de salazones de Rosas, en la escombrera de Gardanne y en la Antigua Audiencia de Tarragona. La forma 103, además, es también inexistente en Marsella.

Por otro lado, la aparición de decoraciones del estilo E (fig. 4, 12-14) nos delimita un poco más la cronología de la escombrera, dándonos un término post-quem de 480 (Hayes, 1972: 221-222). Así pues, sólo fijándonos en la T.S. Africana D podemos ya extraer una cronología bastante fiable: la mayoría de los fragmentos fechables puede situarse entre los años 480 y 520 , datación que, grosso modo, coincidiría con los conjuntos afines de Rosas, Gardan- ne y Marsella, y que sería ligeramente posterior al de la Antigua Audiencia de Tarragona.

Por lo que respecta a las ánforas, las formas identificadas (clasificación Keay) son las siguientes:

- f. XIII A (225-450): 2 ejemplares.

-f. XIX A (275-450): 3 ejemplares.

- f. XXIII (275-425): 1 ejemplar.

- f. XXV E (300-425): 1 ejemplar.

- f. XXV V (300-450): 1 ejemplar.

- f. XXXV B (425-550): 1 ejemplar.

-f. LV A (475-600): 1 ejemplar.

- f. LVII B (425-550): 1 ejemplar.

- f. LXII (425-625): 4 ejemplares.

- f. LXII A (440-625): 1 ejemplar.

- f. LXII Q (425-525/50): 2 ejemplares.

A tenor de los datos actualmente conocidos, las ánforas de fabricación bética aquí representadas (f. XIII A y XIX A; fig. 4, 19) tendrían un carácter residual, pues su datación no parece superar el ecuador del siglo v (Keay, 1984: 142, 146 y 160), aunque, a la luz de nuevas investigaciones, quizá deberán retrasarse unos años su momento final (Remolà, 1993: 157-161 y 164-165). Sea como fuere, la mayoría de las ánforas importadas en esta fase en nuestro yacimiento son ya africanas. Destaca la forma Keay LXII, representada básicamente por dos de sus variantes que ofrecen un inicio de producción más antiguo, como la Q y la A (fig. 4, 21), muy extendidas en la segunda mitad del siglo v (Keay, 1984: 348-350). En este sentido, debemos hacer constar que algunas variantes de esta ánfora proceden de la U.E. 29 de la factoría de Rosas (Nieto, 1993: 104), donde es claramente la forma predominante. Por otro lado, es también destacable el borde de la forma Keay LV A (fig. 4, 23), que no parece que se pueda datar antes del último cuarto del siglo v (Keay, 1984: 293; Remolà, 1993: 155), lo cual ayudaría a consolidar el término post quem de 480 ofrecido por la T.S. Africana D.

\section{Fase $V$}

Sin duda, una de las novedades más interesantes que aportó la excavación fue el hallazgo de un gran nivel de relleno que cubría la práctica totalidad del área intervenida, a lo largo de sus $250 \mathrm{~m}$. Este gran estrato enterraba y obliteraba los silos de la fase III, las tumbas y estructuras de la fase IVa y el vertedero de la fase IVb, a la vez que servía de nivelación del terreno y de cimentación de unas construcciones y muros que aparecieron desgraciadamente muy destruidos debido a su superficialidad (Llinàs et alii, 1994: 193-197). 

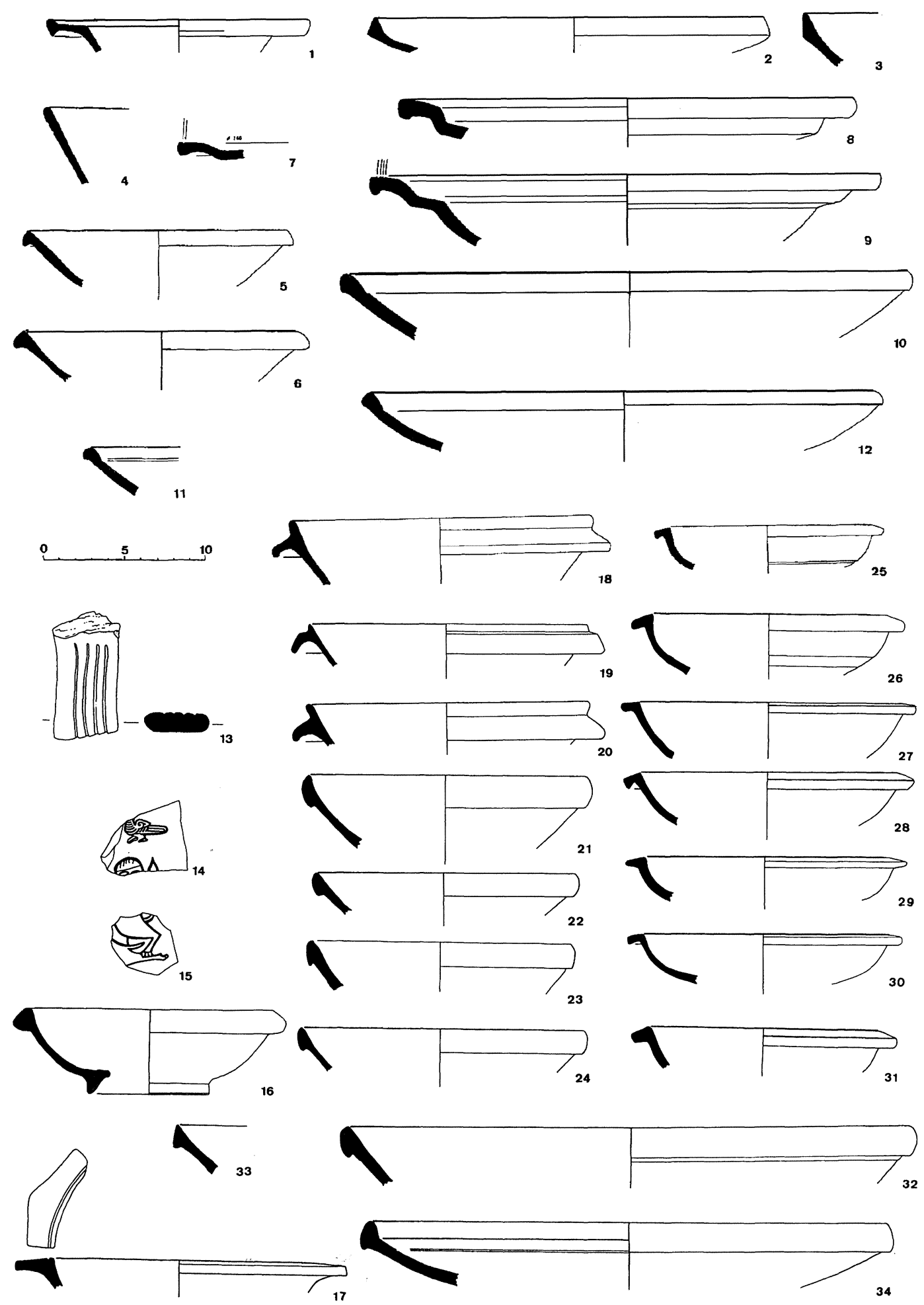

Fig. 5.-Fase V. T.S. Africana C: 1-Hayes 73. T.S. Africana D: 2 y 3-Hayes 61; 4-Hayes 80A; 5 y 6-Hayes 80B; 7 a 9-Hayes 67; 10 a 12-Hayes 87B; 13-asa; 14 y 15-decoración estilo E (ii); 16-Atlante XLVI, 8-10; 17-Hayes 97; 18 a 20-Hayes 91C; 21 a 24-Hayes 99; 25 a 31-Hayes 94; 32-Hayes 103B; 33-Hayes 103A; 34-Hayes 104A. 
Los materiales arqueológicos hallados en este relleno indican que su formación fue muy rápida, hecho que parece indicar una instantánea y planificada urbanización de esta zona del oeste de la ciudad romana de Ampurias durante el siglo vi. No nos podemos pronunciar de momento sobre la naturaleza de este hábitat extramuros, pero el hallazgo mediante fotografía aérea de una gran zona edificada justo al oeste de nuestra excavación (Nolla, 1993: 218-220), induce a pensar en una villa (?) de dimensiones extraodinarias o en un posible barrio periférico. En cualquier caso, es un indicio más que cuestiona las ya trilladas tesis existentes sobre la decadencia ampuritana de la Antigüedad Tardía.

La T.S. Africana D hallada nos permite situar el momento de nivelación de la zona y de construcción de los muros de la fase $\mathrm{V}$ dentro del segundo cuarto avanzado-mediados del siglo vi, y el resto de tipos cerámicos no contradice esta cronología. Debemos hacer constar que el material no permite detectar diferencias cronológicas apreciables ni entre las partes más alejadas de los 250 metros de longitud que abarca la zona excavada. A pesar de ello, no podemos evitar las lógicas reservas surgidas del hecho de que los materiales de esta época presentan unas dataciones un poco imprecisas, y somos conscientes de que una diferencia de una o dos décadas es sumamente difícil de percibir. Sin embargo, incluso aceptando este supuesto, debemos reiterar que el hecho de una edificación planificada y muy rápida de la zona es de una evidencia indiscutible.

La T.S. Africana ha proporcionado un buen número de formas, distribuídas de la siguiente manera:

-f. 58 (300-375): 1 ejemplar.

- f. 59 (320-420): 9 ejemplares.

- f. 60 (320-400): 1 ejemplar.

- f. 61 indet. (325-450): 6 ejemplares.

-f. 61 A (325-450): 7 ejemplares.

-f. 61 B (380-450): 3 ejemplares.

-f. 67 (360-470): 8 ejemplares.

- f. 69 (425-450): 1 ejemplar.

-f. 73 (375-475); 3 ejemplares.

-f. 80 A (400-500): 2 ejemplares.

-f. 80 B (400-500): 4 ejemplares.

- f. 87 indet. (440-525): 1 ejemplar.

-f. 87 A (440-500): 2 ejemplares.

-f. 87 B (440-525): 12 ejemplares.

-f. 87 C (475-525): 1 ejemplar.

- f. 91 indet. (350-650): 29 ejemplares.

-f. 91 A-B (390-530): 9 ejemplares.

- f. 91 C (440-600): 12 ejemplares.

-f. 91 D (600-650): 2 ejemplares.
- f. 93 indet (450-575): 11 ejemplares.

- f. 93 A (450-525): 2 ejemplares.

- f. 93 B (500-575): 20 ejemplares.

- f. 94 indet (425-600): 9 ejemplares.

- f. 94 B (425-600): 11 ejemplares.

-f. 97 (500-575): 1 ejemplares.

-f. 99 (440-650): 47 ejemplares.

-f. 103 A (500-600): 4 ejemplares.

-f. 103 B (500-575): 2 ejemplares.

-f. 104 A (425-600): 8 ejemplares.

-f. 104 B (475-600): 5 ejemplares.

-f. Atlante XLVI, 9-10 (400-600): 2 ejemplares.

- f. indeterminadas: 4 ejemplares.

- dec. estilo E (ii) (525-600): 2 ejemplares.

Este conjunto tan amplio y variado de materiales permite extraer una serie de conclusiones cronológicas bastante precisas a pesar de las dataciones tan laxas de la mayoría de las formas y de la presencia de material más antiguo.

Para empezar, debemos señalar que el término post quem viene dado por las dos bases decoradas con punzones del estilo E (ii), que Hayes data a partir de 525/530 (Hayes, 1972: 222) (fig. 5, 14-15). Aunque de forma no tan precisa, podremos comprobar cómo el análisis de las formas mayoritarias está de acuerdo con esta fecha.

Respecto a la fase IVb tenemos una serie de formas nuevas: 93 A, 93 B, 97, 103 A, 103 B, 104 A y $104 \mathrm{~B}$, la mayoría de las cuales (excepto la $93 \mathrm{~A}$ y la $104 \mathrm{~A}$, un poco anteriores) tienen su inicio de producción en torno al año 500 (Atlante, 1981: 99, 101 y 111; Reynolds, 1987: 78).

Es interesante constatar cómo las formas más extendidas en esta fase presentan su momento álgido de producción a partir del año 525 . Con 47 ejemplares, la forma 99 (fig. 5, 21-24) es la más representada, tal como hallábamos ya en la fase anterior. Esta forma, una de las de más éxito en T.S. Africana $\mathrm{D}$, presenta sus mayores porcentajes en contextos de 525-535 (Reynolds, 1987: 60). El segundo cuarto del siglo vi es también donde podemos situar la mayor parte de los ejemplares de las formas $91 \mathrm{C}$ (fig. 5, 18-20) y 103 A y B (fig. 5, 32-33) (Reynolds, 1987: 30 y 70). Las formas 93 B y 94 B (fig. $5,25-31$ ), que probablemente formaban un servicio, son muy abundantes en el segundo y tercer cuarto del siglo vi (Reynolds, 1987: 40), mientras que la 104 (fig. 5, 34), aún tímidamente presente en el siglo $\mathrm{V}$, conoce su mayor expansión entre el segundo cuarto y finales del siglo vi (Reynolds, 1987: 78). También las asas planas y estriadas, de las cuales tenemos un ejemplar (fig. 5, 13), serían típicas del siglo VI, especialmente en la segunda mitad (Bonifay, 1983: 315). 

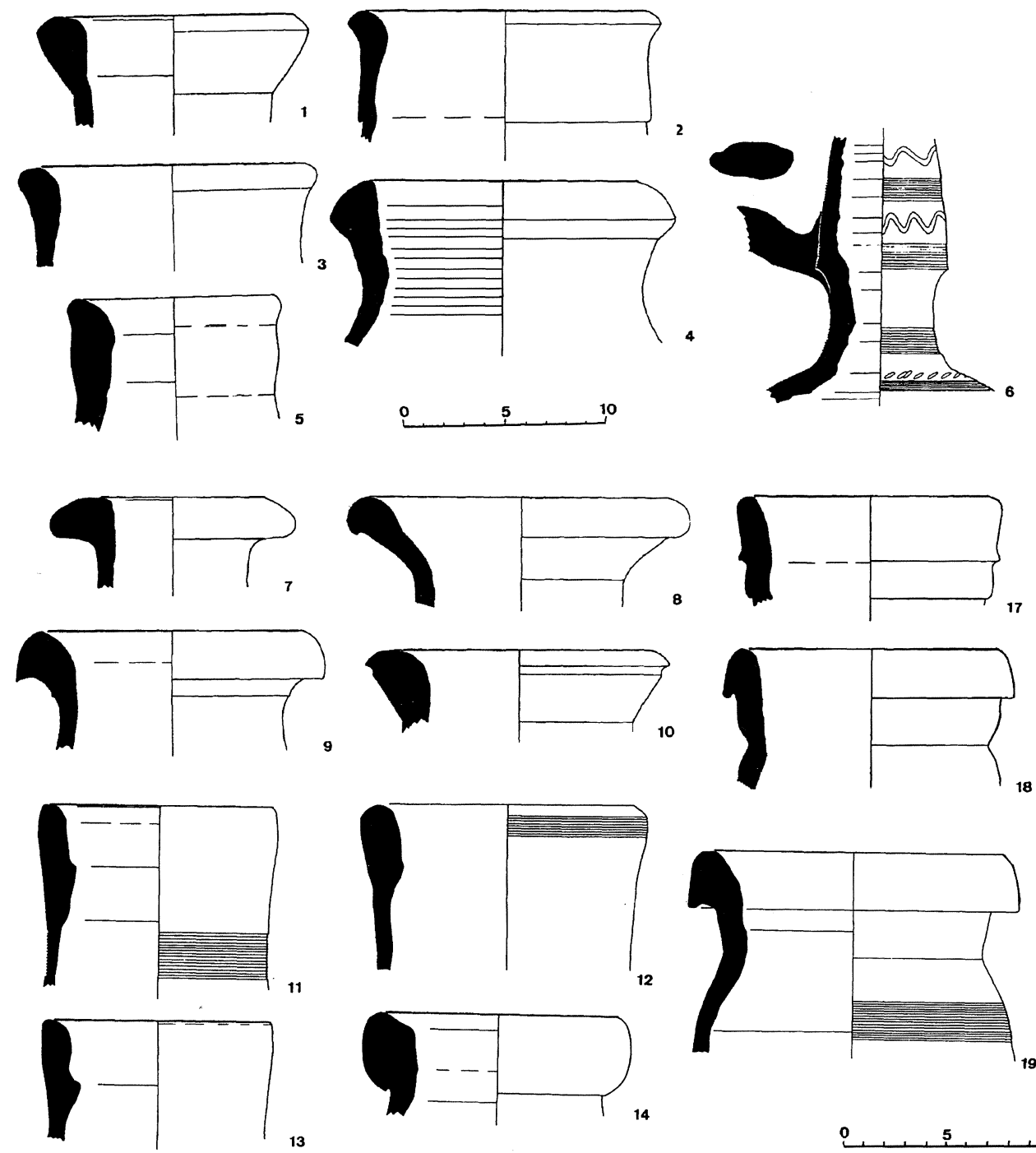

13
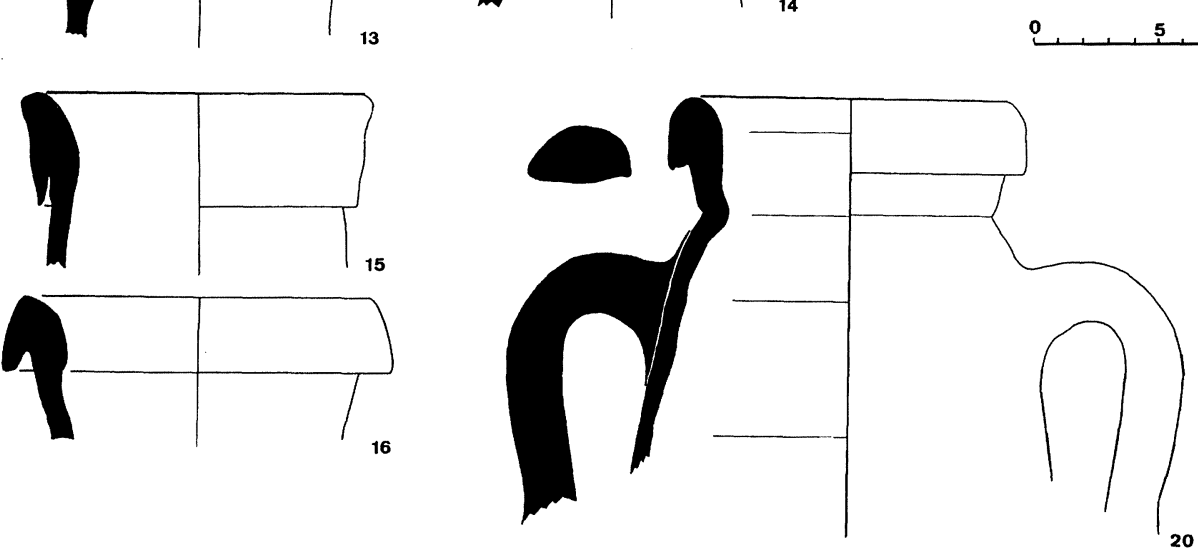

Fig. 6.-Fase V. Ánforas: 1-Keay IIIA; 2-Keay VIIIA; 3-Keay VII; 4-Keay XIIIA; 5-Keay LIII; 6-Keay LXXIX; 7-Keay XXXVB; 8-Keay XXVG; 9-Keay XXXVA; 10-Keay XXV; 11 a 13-Keay LV; 14-Keay LVIIB; 15-Keay LXIA; 17-Keay LXIIQ; 16 y 18-Keay LXII; 19 y 20 -Keay LIIA. 

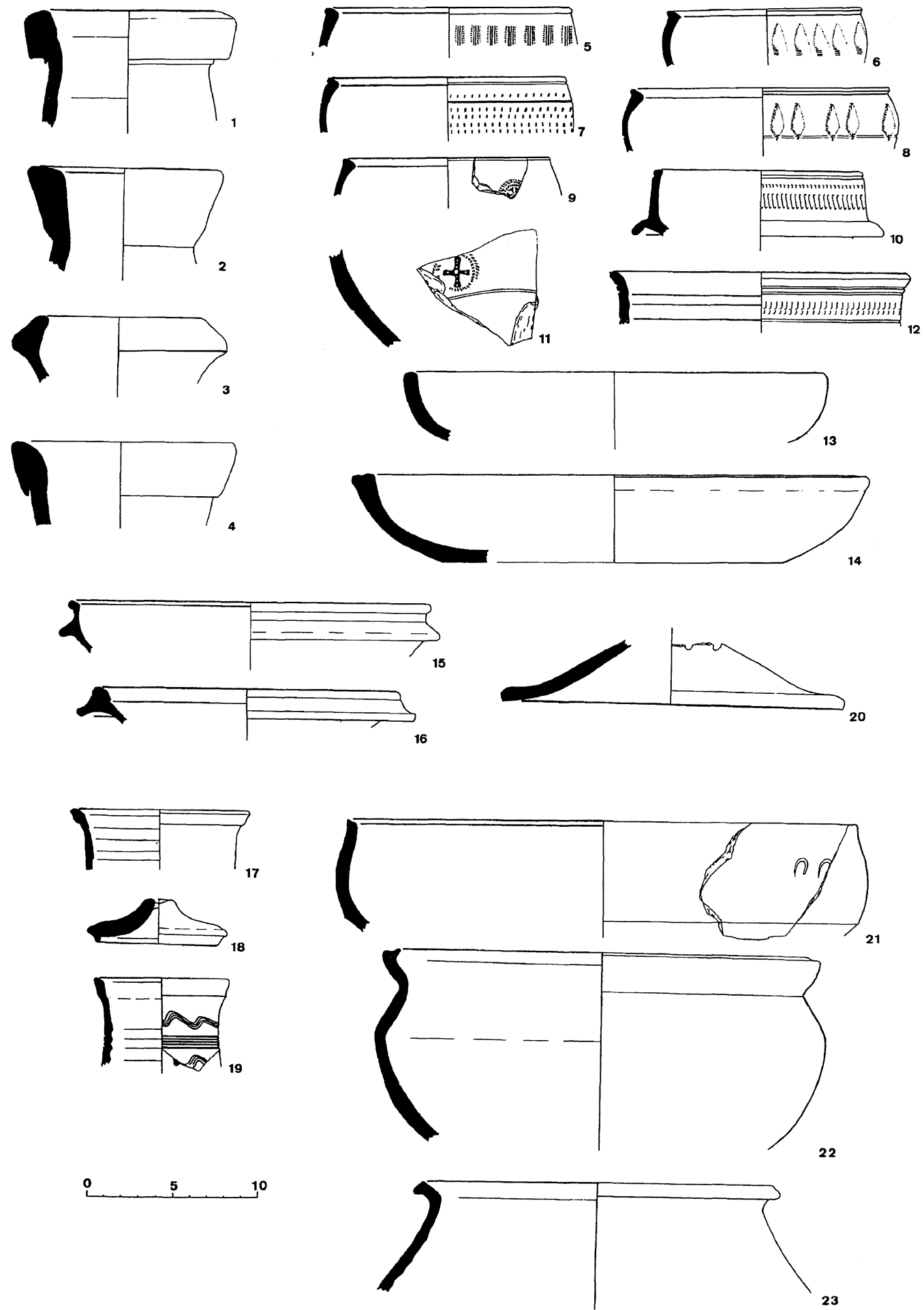

Fig. 7.-Fase V. Ánforas: 1 a 4-indeterminadas. T.S. Paleocristiana: 5 a 9-Rigoir 6; 10-Rigoir 9; 11 -informe decorado; $12-$ Rigoir $18 ; 13$ y 14-Rigoir 4.15 a 19-Común oxidada. 20 a 23-Reducida de cocina. 
Asimismo, encontramos todavía bien representada la forma 87, especialmente la variante B (fig. 5, 10-12), que se continúa produciendo al menos durante el primer cuarto del siglo vi (Hayes, 1972: 136). Sin embargo, este plato, predominante a finales del siglo $\mathrm{v}$ y muy bien representado en nuestra fase IVb, pierde aquí ya parte de su protagonismo y lo cede a los platos típicos de la sexta centuria, como el 103 y el 104.

Las ausencias son también significativas. Dejando de lado dos bordes de Hayes 91 D (600-650), que debemos interpretar sin duda como contaminaciones, no está presente ningún ejemplar de las últimas producciones de T.S. Africana D, con formas que surgirán en la segunda mitad del siglo vi o muy a principios del VII, como la $104 \mathrm{C}$ (a partir ya de 550), 105, 106, 107 ó 109. Esto nos permite descartar con bastante probabilidad una cronología de segunda mitad del siglo vi para esta fase.

Nos hallamos en una época para la cual no se conocen demasiados paralelos. Por su parecido con el nuestro destaca el conjunto del periodo $2 \mathrm{~A} .4 \mathrm{de}$ las excavaciones de la Bourse, en Marsella (Bonifay, 1983: 314-316). La datación -posterior a la nuestra- en la segunda mitad del siglo vi vendría en buena parte corroborada por la existencia de algunas piezas, como un ejemplar casi entero de la forma $104 \mathrm{C}$, una posible 107 y algunos fragmentos de piezas cerradas, que nuestra fase $\mathrm{V}$ no ha proporcionado.

La T.S. Africana D, pues, nos da unos datos que permiten perfilar de manera bastante precisa el momento en que tiene lugar la formación de la fase $\mathrm{V}$. Parece que, con muchas probabilidades, deberíamos situar este momento dentro del segundo cuarto del siglo VI, aunque en una fecha más próxima al año 550 que al 525.

Pasemos a las ánforas. Las formas identificadas (clasificación Keay) se reparten de la siguiente manera:

- f. III -A y B- (200-425): 8 ejemplares.

- f. IV (200-450): 1 ejemplar.

- f. VII (200-450): 1 ejemplar.

- f. VIII (470-550): 5 ejemplares.

- f. XIII A (225-450): 4 ejemplares.

- f. XVI A (200-450): 1 ejemplar.

- f. XIX (275-450): 3 ejemplares.

- f. XXV -indet., B y G- (300-450): 7 ejemplares.

-f. XXXV -A y B- (425-550): 5 ejemplares.

- f. XXXVI B (400-525): 1 ejemplar.

- f. XLV (375-550): 1 ejemplar.

- f. LIII -A i C- (400-675): 6 ejemplares.

- f. LIV (375-650): 2 ejemplares.
- f. LV (475-600): 14 ejemplares.

- f. LVII (450-600): 1 ejemplar.

- f. LXI -A y C- (475-650): 6 ejemplares.

- f. LXII -indet., A, B, D y Q- (425-625): 44 ejemplares.

- f. LXXIX A (475-625): 1 ejemplar.

Se puede ver claramente como el predominio de las ánforas africanas es absoluto. Exceptuando las formas de cronologías claramente anteriores, sólo los seis ejemplares de Keay LIII y los dos de Keay LIV, de procedencia oriental y de cronología muy laxa, rompen la unanimidad de las ánforas africanas del momento. Este fenómeno ha podido ser observado también en la Antigua Audiencia de Tarragona, donde se aprecia en los contextos del siglo vi un brusco descenso de la importaciones de ánforas orientales y sudhispánicas (Remolà y Vallverdú, 1993: 164 y 165). Con 44 individuos identificados, la forma Keay LXII (fig. 6, 17-20) se muestra como la más típica del siglo vI, hecho sobradamente comprobado también en Rosas, en la mencionada U.E. 29, o en una escombrera (U.E. 287) formada casi exclusivamente por ánforas de este tipo y datada en la primera mitad del siglo VI (Nieto, 1991: 102; Nieto, 1993: 62-63). Otras ánforas africanas bien representadas, con seis individuos cada una, son la Keay VIIIA (fig. 6, 2), LV (fig. 6, 11-13) y la LXI (fig. 6, 15). Respecto a esta última debemos mencionar que, aunque mucho más frecuente en el siglo VII (Bonifay y Piéri, 1995: 105-106), su presencia en nuestra fase $\mathrm{V}$ demuestra que también se fabricaba en momentos ligeramente anteriores, como ya había avanzado Keay (Keay, 1984: 306-309).

\section{Fase VI}

Debido a la erosión natural y a los trabajos agrícolas, la última fase del yacimiento está compuesta solamente por el relleno superior de un pozo localizado en la zona central de la parte excavada, cerca de la carretera. Este relleno ha proporcionado el conjunto de materiales arqueológicos de datación más tardía, sin duda posterior al momento de terraplenado y construcción de las estructuras de la fase $\mathrm{V}$ y podría indicar, aunque no de manera totalmente segura, el momento final de la ocupación del lugar.

Los elementos que proporcionan dataciones concretas corresponden de nuevo a las cerámicas africanas de importación y a las ánforas, mientras que las cerámicas de importación del sur de la Galia, presentes todavía en la fase inmediatamente anterior, son aquí absolutamente inexistentes (fig. 2, 2). 
Analizado el material, debemos datar el relleno superior del pozo a partir del año 600 , según deducimos de término post quem proporcionado por la forma Hayes 109 de T.S. Africana D. Lo más lógico es que nos encontremos en un contexto de pleno siglo VII $-\mathrm{o}$ quien sabe si incluso más tardío-, difícil de precisar mientras no podamos incidir más profundamente en el estudio de las cerámicas comunes de este momento. Debemos tener en cuenta que en el siglo vil la llegada de importaciones de T.S. Africana $\mathrm{D}$ se ha convertido ya en un hecho casi episódico y, consiguientemente, la escasa presencia de materiales datables en esta época no nos debe extrañar.
Por otro lado, como veremos, la proliferación de cerámicas comunes reducidas de cocina, en contraste con los porcentajes todavía escasos de la fase inmediatamente anterior, denota el transcurso de un lapso de tiempo indefinido, pero sin duda bien evidente, desde el momento de construcción del hábitat del siglo vi.

La T.S. Africana (exclusivamente tipo D) se encuentra representada solamente por cinco fragmentos, con un repertorio formal reducido a un borde de la forma $104 \mathrm{C}$ (fig. 8, 2) y a otro de la 109 (fig. 8, 1), ambas inéditas en las fases anteriores. Hayes sitúa la forma $104 \mathrm{C}$ dentro de los tres cuartos de siglo que

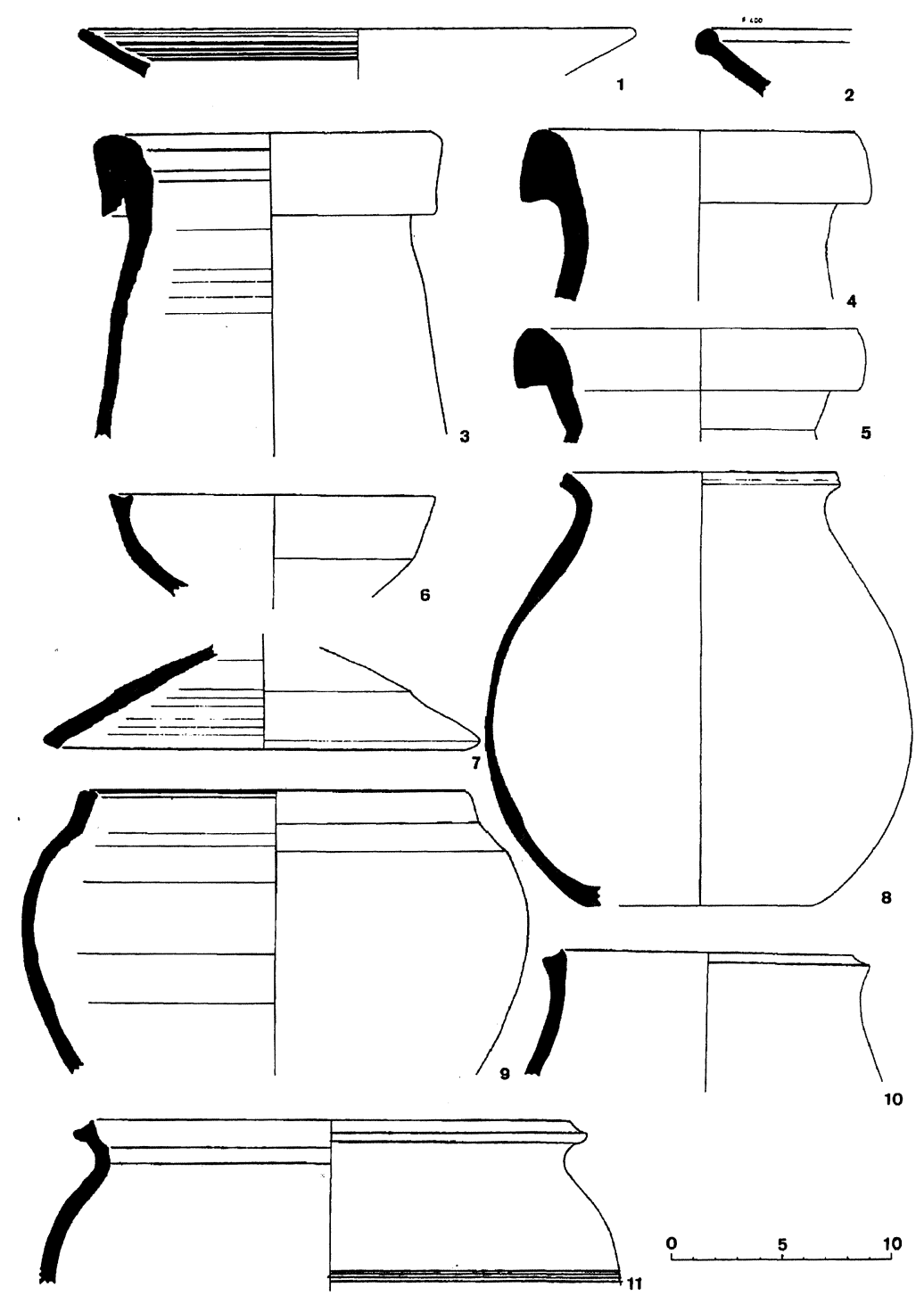

Fig. 8.-Fase VI. T.S.Africana D: 1-Hayes 109; 2-Hayes 104C. Ánforas: 3-Keay LXID; 4 y 5-Keay LXII. 6 a 11-Reducida de cocina. 
van desde 550 hasta 625 (Hayes, 1972: 166), y parece que el momento álgido de esta forma tendría lugar alrededor del año 600 (Reynolds, 1987: 78). A su vez, la forma 109 es una de la más tardías y la podemos situar plenamente dentro del siglo vil (Hayes, 1972: 172). Uno de los pocos contextos paralelos de que disponemos es el periodo $2 \mathrm{~B}$ de las excavaciones de la Bourse, en Marsella, datado en la primera mitad del siglo vir. En este periodo la forma 109 es, junto con la 99, la predominante dentro del repertorio de T.S. Africana D (Bonifay, 1983: 317-322).

Las ánforas llegan todavía con asiduidad en esta época, tal como parecen demostrar los 195 fragmentos recuperados, la inmensa mayoría informes, que constituyen el $55^{\prime} 87 \%$ del total de los materiales cerámicos de la fase. Contamos con cinco bordes, tres de los cuales pertenecen a la variante D de la forma Keay LXI (fig. 8, 3), un ánfora muy extendida en el siglo vII (Bonifay y Piéri, 1995:.105-106). Asimismo, la forma LXII (fig. 8, 4-5), aunque típica del siglo vi, continúa produciéndose también más allá del año 600 bajo la forma de una variante evolucionada (Bonifay y Piéri, 1995: 103). El borde restante pertenece a la forma Keay XXXV A, que, con una cronología que no va más allá de mediados del siglo vi (Keay, 1984: 235 y 240), debemos considerar como residual.

\section{ALGUNAS APORTACIONES A LA EVOLUCIÓN DE LOS CONTEXTOS CERÁMICOS TARDÍOS EN EL LITORAL CATALÁN}

\section{El descenso de las importaciones de cerámica fina}

Las importaciones de vajilla de cierta calidad experimentan una contenida pero continuada curva descendente a lo largo de las fases IVa (8'20\% del total de materiales cerámicos), IVb (6'90\%) y V (4'80\%), que se acentúa de forma repentina al llegar a las tardías cronologías de la fase VI, donde este material representa tan sólo un 1' $42 \%$ del total de los materiales cerámicos (fig. 2, 3). La disminución contenida que se produce a lo largo de los siglos IV, V y VI nos indica un fenómeno sobradamente detectado por doquier, que a menudo ha sido interpretado como el indicio de una importante reducción de los intercambios entre las diversas regiones del Mediterráneo. Sin embargo, el fenómeno de la repentina aceleración de esta tendencia a partir, aproximadamente, de la segunda mitad del siglo vi -comprobado en otros yacimientos y que encontraríamos reflejado en nuestra fase VI- quizá sea debi- do en mayor medida a una caída de la producción de T.S. Africana D que a una aceleración brusca en el descenso de las relaciones ultramarinas. En este sentido, es interesante comprobar los datos que aportan los hallazgos de ánforas (comentados más abajo), material que, por su naturaleza, nos ayudará a evaluar las fluctuaciones del comercio marítimo en mucha mayor medida que la cerámica fina.

La Terra Sigillata Africana es sin duda el material fino de importación más abundante a lo largo de todo el periodo estudiado. Si exceptuamos unos pocos fragmentos del tipo C (C4), de las fases IVa y $\mathrm{V}$, casi la totalidad de los fragmentos pertenecen al tipo $\mathrm{D}$, siendo la producción D1 mayoritaria en la fase IVa y la D2 en las fases IVb, V y VI.

Es importante, sin embargo, destacar el menor porcentaje de T.S. Africana D que refleja la fase IVa, donde, con 73 fragmentos, constituye el 39' $89 \%$ del total de las importaciones de vajilla fina tardía, superando por poco el $37^{\prime} 70 \%$ de la T.S. Lucente y a una mayor distancia de la T.S. Paleocristiana $(22,40 \%$ ) (fig. 2, 2). Este fenómeno desaparece por completo en las fases posteriores. Así, en la fase IVb la T.S. Africana D constituye el 81 '38\% de la vajilla de importación tardía, en la fase $\mathrm{V}$ el 71'60\% y en la fase VI los únicos cinco fragmentos de cerámica fina de importación son, precisamente, de T.S. Africana D.

El segundo y tercer lugar están ocupados por la T.S. Lucente y la T.S. Paleocristiana, respectivamente, es decir, las importaciones procedentes del sur de la Galia. Estos dos tipos cerámicos constituyen casi la totalidad del resto del material fino de importación bajoimperial en las fases IVa, IVb y V. Este hecho concede a las relaciones cerámica africana-cerámica gálica una gran importancia que las hace merecedoras de ser tratadas en un capítulo aparte.

Absolutamente minoritarias son las cerámicas orientales (Late Roman C y D) y la T.S. Hispánica Tardía. El primer caso puede sorprender, pues no es raro encontrar en yacimientos cercanos estratigrafías de los siglos v y vi siempre con un pequeño porcentaje de materiales orientales, especialmente Late Roman C (Nieto, 1984). Su total inexistencia en nuestro yacimiento es ciertamente extraña, pero no podemos hacer otra cosa que consignarla y especular sobre las causas de esta ausencia, provocada al parecer porque un azar desfavorable se ha sumado a la escasez habitual propia de estas cerámicas. Por lo que respecta a las producciones hispánicas tardías, en cambio, no es raro que dispongamos tan solo de un único ejemplar, procedente de la fase $\mathrm{V}$, ya que su presencia en yacimientos costeros del noreste de la Tarraconense es casi siempre episódica. 


\section{Producciones africanas y producciones gálicas}

Pocas novedades podemos aportar a la evolución de las diversas formas de T.S. Africana D, bien estudiadas por un buen número de investigadores. Los hallazgos de la carretera de San Martín parecen confirmar los datos hasta ahora disponibles y proporcionan interesantes conjuntos con cronologías bien establecidas. El único elemento destacable procede de la comparación efectuada entre el material de la fase IVb y los conjuntos excavados en la Antigua Audiencia de Tarragona (Aquilué, 1993), que demuestran que formas como la Hayes 91C y 99, si bien se encuentran ya presentes a partir de mediados del siglo $\mathrm{v}$, son todavía muy escasas a finales de esta centuria y no es hasta los inicios del siglo VI cuando se detectan en cantidades abundantes. Algo parecido ocurre con las formas Hayes 93, 94, 103 y 104, que -a tenor de nuestros hallazgos de las fases IVb y V- no serán frecuentes hasta bien entrada la primera mitad del siglo VI.

Un caso diferente lo constituyen las importaciones gálicas, peor conocidas y a menudo infravaloradas a causa de la incertidumbre de sus aportaciones de valor cronológico. Los hallazgos de nuestro yacimiento ayudan a concretar un poco los principales rasgos de estas importaciones, proporcionándonos un cuadro que se podría hacer extensivo, grosso modo, a los diferentes yacimientos costeros catalanes.

Presentes ya desde un momento incierto de finales del siglo III, las importaciones de T.S. Lucente parecen alcanzar un punto álgido alrededor del año 400 , tal y como encontraríamos reflejado en nuestra fase IVa. En el mismo momento, hace acto de presencia la T.S.Paleocristiana, de aparición más reciente y que en esta época no ha llegado todavía a su punto de máxima difusión, aunque éste se encuentra ya muy cercano. Esta destacable presencia de importaciones del sur de la Galia, que parece que tendríamos que circunscribir a unos márgenes temporales no demasiado dilatados y situar casi exclusivamente en yacimientos costeros, se traduce en un curioso y hasta ahora poco documentado descenso en las cifras relativas -no absolutas- de T.S. Africana D (Aicart, Llinàs y Sagrera, 1991: 201) (fig. 2, 2).

En la fase IVa de nuestro yacimiento la cantidad de T.S. Lucente es considerable (69 fragmentos, $37^{\prime} 70 \%$ de la cerámica fina tardía), con unos porcentajes muy poco frecuentes y que en las comarcas vecinas sólo encuentran paralelo en algún yacimiento costero con cronologías de finales del siglo IVprincipios del v, como la fase de reformas de la factoría de salazones de Rosas (Martín, Nieto y Nolla, 1979: 175-179 y 194; Aicart, Llinàs y Sagrera,
1991: 199, 201 y 205). Como es habitual en este tipo cerámico, el repertorio formal -de cronología muy amplia- no aporta otras precisiones. Nosotros tenemos 14 bordes de la forma Lamboglia 1/3, la más frecuente en T.S. Lucente (Lamboglia, 1963: 168-170), uno de f. Lamb. 3 y la base de una jarra de las formas Lamb. 14/26 ó 28 (fig. 3, 8).

Más que en explicaciones da carácter exclusivamente cronológico, parece que la anormal abundancia de este tipo cerámico se da a causa de la situación costera de los yacimientos y por el hecho de que su redistribución hacia el interior sería mínima (Aicart, Llinàs y Sagrera, 1991: 205). En este contexto no es extraño que -aparte de Rosas y Ampurias- su presencia sea relativamente abundante en Llafranc (Barti y Plana, 1989: figs. 4, 5 y 6), Sant Feliu de Guíxols (Esteva, 1962: 42-48), la villa romana de Pla de Palol, en Platja d'Aro (Aicart, Llinàs y Sagrera, 1991: 203 y 206), y la de Els Ametllers, en Tossa de Mar (Batista, López y Zucchitello, 1980: láms. III y IV), y en cambio sea casi inexistente en estaciones no costeras, como la villa del Camp de la Gruta (Nolla y Puertas, 1988), la de Puig Rodon (Nolla y Casas, 1990: 218) o Vilauba (Roure et alii, 1988), entre otras.

La T.S. Paleocristiana, un tipo de cerámica que empieza a fabricarse en el sur de la Galia durante el tercer cuarto del siglo iv y que alcanza su mayor éxito de difusión en la primera mitad del siglo $\mathrm{v}$ (Rigoir, 1968: 192; Martin, 1971: 142 y 145; Raynaud, 1982: 348), se encuentra también presente en la fase IVa en porcentajes elevados. De los 41 fragmentos exhumados (22'40\% de la cerámica fina tardía de esta fase), 14 son anaranjados y 27 grises. Juntos forman un conjunto nada despreciable si tenemos en cuenta la general escasez de este tipo de cerámica en el ámbito de estudio que nos ocupa. Las formas identificadas son las más frecuentes: $1,3,4,6,8,15$ y 18, aparte de fragmentos sin forma decorados (fig. 3, 9-16). Los punzones (rosetas, palmetas, arcos...) son también muy frecuentes y típicos, aunque hay que destacar sin duda la originalidad del motivo animal impreso en la pieza de la fig. 3,15 .

Todos los fragmentos de T.S. Paleocristiana recuperados en esta fase pertenecen a la producción languedociense (Rigoir, 1968: 181-186; Rigoir y Rivet, 1985: 89), área de donde procede la mayoría de T.S. Paleocristiana importada en el actual territorio catalán, tal y como se puede comprobar sobradamente en Rosas (Llinàs, 1991: 129-132), Barcelona (Bourgeois, 1973: 69-93), Solsona (Rigoir, 1971: 67), Lérida (Junyent y Pérez, 1985: 903-914) y Tarragona (Rigoir, 1971: 67; TED’A, 1989: 156-172), entre otros muchos lugares. 
Un siglo después, alrededor del año 500, el panorama es muy diferente. Nuestra fase IVb parece demostrar como la T.S. Lucente está ya a punto de desaparecer del mercado y la T.S. Paleocristiana se encontraría ya en un momento avanzado de su decadencia, de manera que la mayor parte de las importaciones de cerámica fina correponde ya a la T.S. Africana $\mathrm{D}$ de forma indiscutible.

El porcentaje de importaciones gálicas, pues, disminuye sensiblemente respecto a la fase anterior (fig. $2,2)$. Con 12 fragmentos (6'38\% del total de la vajilla de importación tardía), la T.S. Lucente ha experimentado un considerable bajón. Sin embargo, debemos hacer constar que se ha demostrado una presencia nada despreciable de este tipo cerámico en contextos languedocienses de mediados-finales del siglo $\mathrm{v}$, representado básicamente por las formas $1 / 3$ y 3 ó 3/8 (C.A.T.H.M.A., 1986: 39), que precisamente son, con 3 y 2 ejemplares respectivamente, las dos formas identificadas en nuestra escombrera. Aunque un conjunto tan pequeño no nos permita asegurarlo, parece que, aunque ya de forma muy reducida, las importaciones de T.S. Lucente habrían continuado llegando a Ampurias hasta este momento.

La T.S. Paleocristiana se encuentra en esta fase $\mathrm{IVb}$ en proporciones ligeramente superiores a la Lucente, con 23 fragmentos (18 grises y 5 anaranjados), que constituyen el 12 '23\% del total de la vajilla de importación tardía. Como en la fase anterior, todos pertenecen a la producción languedociense $y$, aunque se puede constatar un evidente descenso, parece que la llegada de este tipo cerámico continuaría produciéndose en estos momentos en la costa catalana. De las siete formas identificadas, dos pertenecen a la forma Rigoir 6 , dos más a la 8 , mientras que la 1 y la 4 se encuentran representadas cada una por un ejemplar (fig. 4, 15-18). Una séptima pieza, fragmentada, puede pertenecer a las formas 1, 2 ó 3. También hay algunos fragmentos informes decorados. Los punzones localizados (palmetas, rosetas, arcos, columnitas) son también tipicamente languedocienses.

Por desgracia, no disponemos de una evolución cronológica fiable para el grupo languedociense de la T.S. Paleocristiana, y los yacimientos de Marsella y de Gardanne no nos sirven, dado que se encuentran dentro del área provenzal y a este grupo pertenecen los fragmentos de T.S. Paleocristiana de que disponemos. La U.E. 29 de Rosas, con nueve fragmentos (dos de los cuales son provenzales), constituiría el único paralelo destacable, pero no nos aporta ningún dato concreto (Llinàs, 1991: 134), ya que las piezas de este conjunto no presentan afinidades claras con las del nuestro.
Nos vemos en cambio obligados a mencionar dos yacimientos costeros catalanes que presentan cronologías ligeramente anteriores: la Antigua $\mathrm{Au}-$ diencia de Tarragona, ya citada anteriormente, y Can Modolell, en Cabrera de Mar (Barcelona). En estos conjuntos, sin duda de la segunda mitad del siglo $\mathrm{v}$, predominan de forma clara las importaciones de T.S. Paleocristiana de la Provenza (Aquilué, 1993: 147; Clariana y Jàrrega, 1990), lo que ha hecho pensar en una posible desaparición de las importaciones languedocienses a partir de mediados del siglo $\mathrm{v}$, nunca plenamente confirmada (Bacaria, 1993: 374). Ante nuestros hallazgos debemos matizar, en todo caso, esta hipótesis y considerar que, si bien es innegable el predominio provenzal durante el periodo $450-500$ y su continuidad -mitigada- en la primera mitad del siglo vi, la llegada de importaciones languedocienses, posiblemente más fuerte en el Ampurdán por cuestiones de proximidad geográfica, no habría cesado del todo y continuaría produciéndose todavía alrededor del año 500 .

Por lo que respecta a los datos de la fase V -segundo cuarto avanzado del siglo vI-, debemos hacer constar que se encuentran ligeramente falseados debido al numeroso material residual de las fases I y IVa que contienen sus unidades estratigráficas, y eso hace que, desgraciadamente, no sirvan para ilustrar de manera clara la caída definitiva de las importaciones de vajilla fina gálica, aquí presentes en porcentajes engañosamente demasiado elevados.

La T.S. Lucente, por ejemplo, parece experimentar una sensible recuperación (14'77 \% del total de la vajilla de importación tardía; fig. 2,2 ), que consideramos fruto de la mencionada presencia de material residual en los estratos de la fase V. Sin descartar que todavía pudiese llegar a producirse en pequeñas cantidades durante los primeros años del siglo vi (C.A.T.H.M.A., 1986: 39), es muy probable que en la época en que se forma nuestra fase $\mathrm{V}$ ya hubiese desaparecido del mercado. Desgraciadamente, disponemos actualmente de muy pocos datos fiables para comprobar este extremo, si bien algunos de ellos parecen confirmar la decadencia de este tipo cerámico a inicios del siglo vi (Pelletier et alii 1991: 338 y fig. 9). Los fragmentos identificados en la fase $\mathrm{V}$ pertenencen a las formas Lamboglia $1 / 3$ (20 ejemplares) y 3 (2 ejemplares).

Algo parecido ocurre con la T.S. Paleocristiana, que aquí se encuentra representada por un total de 71 fragmentos (8'32\% del total de la vajilla de importación bajoimperial; fig. 2, 2), 40 de los cuales son anaranjados y 31 grises. De nuevo las piezas provenientes de Languedoc componen casi la totalidad de los fragmentos. No obstante, y a pesar de los fragmentos 
localizados en nuestra fase IVb, con los conocimientos hoy en día disponibles es difícil asegurar que la variante languedociense de este tipo cerámico se continuase produciendo y exportando con asiduidad en una fecha tan tardía; su momento álgido se podría situar a finales del siglo Iv y a principios del v, y, por el momento, no podemos ofrecer paralelos que ayuden a esclarecer el panorama de su decadencia y desaparición. El estado fragmentario y desgastado de muchas de las piezas halladas en esta fase hace suponer que nos encontramos ante ejemplares residuales, pero es imposible distinguir, si realmente existe, alguna diferencia cronológica entre ellos. Las formas identificadas se reparten de la siguiente manera: $f$. Rigoir 2 ó 3 A: 2 ejemplares; f. 4: 3 ejemplares; f. 6: 5 ejemplares; f. 8: 2 ejemplares; f. 9: 1 ejemplar; f. 15: 1 ejemplar; f. 18: 1 ejemplar. Debemos destacar, también, algunos fondos de plato ricamente decorados y varios punzones de los tipos más habituales (fig. 7, 5-14).

Cabe señalar la presencia de tres fragmentos - un borde de f. 18 (fig. 7,12), un fondo de plato y un fragmento de pared decorado con un motivo cruciforme (fig. 7, 11)- de aspecto inequívocamente provenzal (Llinàs, Nolla y Nieto, 1996-97: 1063-1065), los únicos localizados en la excavación. Al contrario de lo que pasa con la languedociense, la evolución de la variante provenzal es mucho más conocida y cuenta con algunas evidencias datables claramente en el siglo VI, que prueban la continuidad de su producción en esta época (Bonifay, 1983: 327-334; Cavaillès-Llopis, 1986: 177-180; Pelletier et alii, 1991: 282-302 y 338-339). Estos datos podrían explicar la abundancia de piezas provenzales en algunos contextos catalanes datados a partir de la segunda mitad del siglo $\mathrm{v} y$, por lo tanto, ligeramente anteriores a nuestra fase V (Almagro, 1964; Clariana y Jàrrega, 1990; Aquilué, 1993), a la vez que delatarían como probablemente residual una parte por otro lado difícil de cuantificar- de las piezas languedocienses de esta fase.

Los estratos pertenecientes a la fase VI (siglo vir o principios del viII) no contienen ningún fragmento de cerámica gálica, lo cual coincide plenamente con los datos hasta ahora disponibles sobre la desaparición de estas producciones en el transcurso del siglo vi.

\section{Las ánforas}

El análisis de los tipos anfóricos de que disponemos revela cómo a partir de mediados del siglo $\mathrm{v}$ se produce un fuerte descenso de las piezas provenientes de la Bética y de Oriente, y las ánforas africanas (reflejadas basicamente en las formas Keay LV y, sobre todo, LXII) se convierten en predominantes de una manera casi absoluta hasta el siglo vII. El otro aspecto a destacar lo constituye el hecho de que a lo largo del periodo que estudiamos no se detecta descenso alguno en la llegada de ánforas al yacimiento, sino más bien todo lo contrario: si alrededor del año 400 representan un tercio del material cerámico recuperado, dos siglos más tarde sobrepasan el $50 \%$. Es indudable que este hecho (sin perder de vista, es cierto, los riesgos inherentes a toda generalización) indica mejor que cualquier otra evidencia que los intercambios comerciales a gran escala entre las costas del Mediterráneo occidental no experimentaron ninguna crisis importante durante los siglos v y vi, a pesar de los grandes cambios políticos representados por el derrumbe del Imperio Romano de Occidente, el establecimiento vacilante de los reinos germánicos y la conquista bizantina de una parte importante de la región.

En la fase IVa, con 799 fragmentos, las ánforas constituyen el 34'13\% del total del material cerámico aparecido. A pesar de estos porcentajes, contamos con sólo cuatro formas, dos de ellas africanas (Keay IV y XXV, una oriental (Keay LIV) y una bética (Keay XVIII). No cabe duda de que es demasiado arriesgado intentar cualquier tipo de generalización a partir de sólo cuatro ejemplares.

En la fase IVb las ánforas constituyen casi la mitad (49'79 \%) de la cerámica extraída de la escombrera (fig. 2,3), porcentaje que supera sensiblemente el de la fase IVa y que se podría asimilar plenamente a los proporcionados por los diversos yacimientos costeros contemporáneos (Nolla y Casas, 1990: figs. 26 y 27). Ya hemos visto en la primera parte de este trabajo cómo en este momento el predominio de las ánforas africanas es ya indiscutible, con formas típicas del siglo v (Keay XXV, principalmente), aunque irrumpen con fuerza los tipos que continuarán produciéndose a lo largo del siglo VI (Keay LXII, sobre todo, pero también Keay XXXV, LV y LVII). A pesar de ello, sin embargo, todavía hacen acto de presencia algunos ejemplares béticos, como la Keay XIII y la Keay XIX.

La fase $\mathrm{V}$, con un total de 8.635 fragmentos (45'47\% del total de los materiales cerámicos de la fase, fig. 2, 3), muestra como las ánforas siguen constituyendo el tipo cerámico más abundante. De nuevo el predominio africano es total y, si exceptuamos los tipos residuales, solamente podemos destacar unos pocos ejemplares orientales (Keay LIII y LIV). Sin duda, la forma Keay LXII es la más típica del momento, aunque no podemos desdeñar la presencia también significativa de las Keay VIII, 
XXXV, LV y LXI. En este aspecto, el repertorio formal de las ánforas de la fase $\mathrm{V}$ es prácticamente idéntico al que pueden presentar otros yacimientos costeros catalanes con cronologías parecidas.

Es destacable el hecho de que, lejos de reflejar una progresiva decadencia, los porcentajes de ánforas en nuestro yacimiento se mantienen firmes e incluso experimentan un ligero aumento en la fase VI (195 fragmentos, 55'87\% del total del material) (fig. 2, 3). Conscientes de nuevo del riesgo que comporta la generalización de los datos, podemos aventurar que aún en el siglo vir los yacimientos costeros catalanes continuarían manteniendo relaciones comerciales más o menos regulares con África, un hecho que podría haber sido disimulado tanto por la ya antes mencionada caída de la producción de T.S. Africana D como por la escasez de conjuntos contemporáneos bien estudiados. En este contexto, hemos podido comprobar visualmente cómo una parte muy importante del conjunto de los materiales extraídos del castrum visigodo de Puig Rom, situado en la vecina Rosas y datado en el siglo viI, está constituido precisamente por ánforas, mientras que la T.S. Africana D es casi inexistente.

\section{La generalización de la cerámica reducida de cocina}

En el campo de las cerámicas de producción local podemos observar cómo las comunes oxidadas predominan sobre las reducidas de cocina en una proporción aproximada de 2 a 1 a lo largo de las fases IVa, IVb y V, a pesar de que se nota un continuo pero muy ligero descenso de las primeras en favor de las segundas.

En la fase IVa, las cerámicas comunes constituyen el material cerámico más abundante (fig. 2, 3), con un total de 1.205 fragmentos (50'62\% del total). De los tipos existentes, las comunes grises y las oxidadas de cocina son muy minoritarias en las diferentes fases tardías del yacimiento. Predominan claramente, con un $65^{\prime} 93 \%$, las comunes oxidadas, mientras que las reducidas de cocina representan un 34'07 \% del total. El repertorio formal de las primeras está formado básicamente por morteros, jarras y jofainas, mientras que las reducidas de cocina están constituidas por las típicas ollas y jarras de perfil en "s" y cazuelas. Entre ellas destacan unas ollas generalmente bastante bajas, de paredes totalmente cóncavas y con dos pequeñas asas horizontales en forma de oreja pegadas a la pared externa (fig. 3, 18). Esta pieza es una de la formas más características de este tipo de cerámica en los yacimientos catalanes durante la antigüedad tardía, y poseemos paralelos claros en la escombrera de Vila-Roma, en Tarragona (TED'A, 1989: 234-238), entre otros lugares.

En la fase IVb las cerámicas comunes ceden un poco de terreno ante las ánforas, y constituyen el 41'99\% del material cerámico de la escombrera (fig. 2, 3). La distribución por tipos y formas es muy parecida a la de la fase IVa, si bien se constata un ligerísimo aumento de la cerámica de cocina en detrimento de las comunes oxidadas y reducidas (fig. 2, 4).

En la fase $\mathrm{V}$ mantienen sus porcentajes respecto a la fase anterior, ya que, con 7.825 fragmentos, constituyen el 41'21\% del total de material cerámico de la fase (fig. 2, 4). Con 4.800 fragmentos, predomina claramente la común oxidada, frente a los 2.827 de la reducida de cocina, de manera que en esta fase se mantiene todavía la relación aproximada de 2 a 1 entre los dos tipos cerámicos. Las comunes grises (122 fragmentos) y las oxidadas de cocina (76 fragmentos) son claramente minoritarias.

El repertorio formal no varía demasiado respecto a las otras etapas. Las comunes grises y oxidadas están representadas básicamente por jarras, morteros con listel (fig. 7, 15-16) y algunos boles y jofainas, a los que cabe añadir algunos fragmentos que presentan varios tipos de decoración, especialmente estriada (fig. 7, 19) o pintada. Las principales formas de cocina se reparten entre tapas (fig. 7, 20), ollas de perfil en "s" y cazuelas. Algún fragmento presenta decoración incisa o incluso estampada (fig. 7, 21-23).

En la fase VI se produce un fenómeno altamente significativo. Las proporciones entre los dos tipos principales de cerámica común (que constituye el 42 ' $17 \%$ del material) se han invertido y un notable conjunto de piezas de cerámica reducida de cocina eclipsa la hasta el momento predominante común oxidada. En porcentajes, las comunes oxidadas solamente conforman el $32^{\prime} 43 \%$ de las cerámicas de fabricación local, pérdida que se ha traducido en el correspondiente aumento de las reducidas de cocina, que llegan a alcanzar el 67'57 \% (fig. 2, 4).

Este último tipo cerámico (fig. 8, 6-11) está representado por un interesante lote de formas muy variadas (boles, jarras, ollas, cazuelas) que ya anuncia de manera clara el tipo de cerámica predominante durante toda la Edad Media. Indiscutiblemente, este material es de gran interés, puesto que documenta de manera bastante precisa la primera fase del gran dominio -desde alrededor del año 600- que las reducidas de cocina ejercerán a lo largo de toda la Edad Media 
cristiana. No se nos escapa, tampoco, la relación existente entre la caída de la vajilla de importación y la eclosión de la cerámica reducida de cocina, aunque es muy arriesgado pensar en la sustitución parcial de una por la otra, sobre todo debido a las grandes diferencias formales y funcionales. Sin embargo, es evidente que el cese de la llegada de la cerámica africana podría haber impelido a los ceramistas locales a aumentar la producción de boles y de platos-tapadera como los de la fig. 8, 6-7.

La falta de contextos contemporáneos bien datados en la región circundante hace que sea de momento imposible pensar en un intento de datación únicamente a través de estas cerámicas, pero el mencionado incremento repentino de su presencia constituye una prueba más para dar a nuestra fase VI una cronología considerablemente baja. En cualquier caso, esperamos que nuestros datos puedan más adelante ser contrastados con nuevos hallazgos, para comenzar así a esclarecer el oscuro panorama de estas épocas hasta el momento tan desconocidas.

\section{BIBLIOGRAFÍA}

Aicart, F.; Llinàs, J.; Sagrera, J., 1991: Primera aproximació a la difusió de la Terra Sigillata Lucente al nord-est de Catalunya, Cypsela, IX, 197-207.

Almagro, M., 1964: Excavaciones en la Palaiápolis de Ampurias. Excavaciones Arqueológicas en España, 27, Madrid.

Aquilué, X., 1992: Las cerámicas de producción africana procedentes de la Colonia Iulia Urbs Triumphalis Tarraco. Tesis doctoral inédita, Universidad de Barcelona.

Aquilué, X., 1993: Las cerámicas finas de los niveles tardo-romanos, en Dupré, X.; CarretÉ, J. M.: La Antiga Audiència. Un acceso al foro provincial de Tarraco. Excavaciones Arqueológicas en España, 165, 117-150.

Atlante, 1981: Atlante delle forme ceramiche. I. Ceramica fine romana nel bacino mediterraneo (Medio e Tardo Impero), Roma. Coordinado por A. Carandini.

BACARIA, A., 1993: Importacions sudgàl.liques $i$ produccions locals de ceràmica estampada a Catalunya durant el Baix Imperi Romà. Tesis doctoral inédita, Universidad de Barcelona.

Batista, R.; López, A.; Zucchitello, M., 1980: Noves aportacions al coneixement de la vil.la romana dels Ametllers. Tossa, Quaderns d'estudis tossencs, 1. Tossa de Mar.

Bonifay, M., 1983: Eléments d'évolution des céra- miques de l'Antiquité tardive à Marseille d'après les fouilles de la Bourse (1980-81), Revue Archéologique de Narbonnaise, XVI, 289-334.

Bonifay, M.; Piéri, D., 1995: Amphores du Vè au VIIè s. à Marseille: nouvelles données sur la typologie et le contenu, Journal of Roman Archaeology, 8, 94-120.

Casas, J.; Castanyer, P.; Tremoleda, J.; Nolla, J. M., 1993: La vil.la romana de la Font del Vilar (Avinyonet de Puigventós, l'Alt Empordà), Annals de l'Institut d'Estudis Empordanesos, 26, 343-372.

C.A.T.H.M.A, 1986: La céramique du Haut Moyen Âge en France méridionale: Élements comparatifs et assai d'interprétation, La ceramica medievale nel Mediterraneo Occidentale. Siena-Faenza, octubre 1984, 27-50.

Cavaillès-Llopis, M. T., 1986: Céramiques de l'Antiquité Tardive a Marseille (corne du port antique, sondages D II 11 et D II 15), Documents d'Archéologie Méridionale, 9, 167-195.

Clariana, J. F.; JÀrrega, R., 1990: Aportación al conocimiento de unas estructuras arquitectónicas tardorromanas del yacimiento arqueológico de Can Modolell (Cabrera de Mar, Barcelona), Archivo Español de Arqueología, 63, 330-344.

EstevA, L., 1983: Ceràmica hispano-romana recollida en el subsòl del monestir de Sant Feliu de Guíxols, Estudis sobre temes del Baix Empordà, 2, 41-60 (reedición de un artículo publicado en 1962).

Hayes, J. W., 1972: Late Roman Pottery. A catalogue of Roman fine wares, Londres.

KeAY, S. J., 1984: Late Roman Amphorae in the Western Mediterranean. A typology and economic study: the Catalan evidence, B.A.R. International Series 196, Oxford.

LlinÀs, J., 1991: La T.S.Paleocristiana de l'edifici baix-imperial de Roses (Campanyes del 1976 al 1985), Trabajo de Investigación inédito, Universidad Autónoma de Barcelona, Bellaterra.

Llinàs, J.; Manzano, S.; Puig, A. M.; Rocas, X., 1992: Noves aportacions al coneixement de les necròpolis emporitanes. Les troballes realitzades en l'excavació d'urgència a la carretera de Sant Martí d'Empúries, Anuari de l'Institut d'Estudis Empordanesos, 25, 353-381.

Llinàs, J.; Manzano, S.; Puig, A. M.; Rocas, X., 1994: Noves dades sobre el poblament d'època visigoda a Empúries: resultats de l'excavació d'urgència a la carretera de St. Martí, Annals de l'Institut d'Estudis Gironins, XXXIII, 189-204.

Llinàs, J.; Manzano, S.; Puig, A. M.; Rocas, X., 1997: L'excavació de la carretera de Sant Martí: 
un sector de l'entorn d'Empúries desde la Baixa República fins a l'Antiquitat Tardana, Estudis Arqueològics, 3, Universitat de Girona, Girona.

Llinàs, J.; Nolla, J. M.; Nieto, F. J., 1996-1997: Iconographie paleocristiana en ceràmiques estampades gàlliques (D.S.P.) trobades al nord-est de Catalunya, Annals de l'Institut d'Estudis Gironins, XXXVII, 1059-1068.

MaCKensen, M., 1985: Prospektion einer Spätantiken Sigillatatöpferei in El Mahrine (Nordtunisien), CEDHAC, Carthage dossiers, 6, 29-39.

Martín, M. A.; Nieto, F. J.; Nolla, J. M., 1979: Excavaciones en la Ciudadela de Rosas (Campañas 1976 y 1977). C.I.A.G. Serie monográfica, 2. C.I.A.G., Gerona.

Martin, T., 1971: Contribution a l'étude de la forme "Rigoir 35" en céramique estampée, Bulletin de la Societé d'Études Scientifiques de l'Aude, LXXI, 139-159.

NiETo, F. J., 1981: Acerca del progresivo despoblamiento de Ampurias, Rivista di Studi Liguri, XLVII, 34-51

NiETo, F. J., 1984: Algunos datos sobre las importaciones de cerámica "Phocaean Red Slip" en la Península Ibérica, Papers in Iberian Archaeology, B.A.R. International Series, 193 (II), Oxford, 540-548.

Nieto, F. J., 1991: La Terra Sigillata Africana en el noreste de la Tarraconense. Tesis doctoral inédita, Universidad Autónoma de Barcelona, Bellaterra.

Nieto, F. J., 1993: El edificio "A" de la Ciudadela de Roses (la Terra Sigillata Africana), Serie Monográfica, 14. C.I.A.G., Gerona.

Nolla, J. M., 1984: Excavaciones recientes en la Ciudadela de Roses. El edificio bajo-imperial, Papers in Iberian Archaeology, B.A.R. International Series, 193 (II), Oxford, 430-459.

Nolla, J. M., 1993: Ampurias en la Antigüedad Tardía. Una nueva perspectiva, Archivo Español de Arqueología, 66, 207-224.

Nolla, J. M.; CASAS, J., 1990: El material ceràmic d'importació de la vil.la romana de Puig Rodon (Corçà, Baix Empordà), d'època severiana a la Baixa Antiguitat, Cypsela, VIII, 193-218.

Nolla, J. M.; Nieto, F. J., 1979: Acerca de la cronología de la muralla romana tardía de Gerunda: la Terra Sigillata Clara de Casa Pastors, Faventia, 1/2, 269-272.

Nolla, J. M.; Puertas, C., 1988: Ceràmiques africa- nes i material d'importació baix-imperial del jaciment del Camp de la Gruta (Torroella de Montgrí, Baix Empordà), Estudis sobre el Baix Empordà, 7, 29-77.

Pelletier, J. P.; Poussel, L.; Rigoir, J. e Y.; VallauRI, L.; Foy, D., 1991: Poterie, métallurgie et verrerie au début du VIè s. à Gardanne (B.-du-Rh.), Documents d'Archéologie Méridionale, 14, 277 350.

Remolà, J. A., 1993: Las ánforas de los niveles tardo-romanos, en Dupré, X.; Carreté, J. M.: La Antiga Audiència. Un acceso al foro provincial de Tarraco, Excavaciones Arqueológicas en España, 165, 151-165.

Reynolds, P., 1987: El yacimiento tardorromano de Lucentum (Benalúa, Alicante): las cerámicas finas, Catálogo de fondos del Museo Arqueológico, I, Alicante.

RigoIR, J., 1968: Les sigillées paléochrétiennes grises et orangées, Gallia, XXVI, 177-244.

Rigorr, J., 1971: Les dérivées des sigillées paléochrétiennes en Espagne, Rivista di Studi Liguri, XXXVII, 33-68.

Rigolr, J. e Y.; Rivet, L., 1985: Les derivées-des-sigillées paléochrétiennes. Exportations et influences entre les groupe provençal et le groupe languedocien, Documents d'Archéologie Méridionale, 8, 87-99.

Rocas, X.; Manzano, S.; Puig, A. M., 1992: L'excavació d'urgència a la carretera de Sant Martí d'Empúries a la carretera d'Orriols a l'Escala, Primeres Jornades d'Arqueologia de les Comarques de Girona, St. Feliu de Guíxols, 125-136.

Roure, A.; Castanyer, P.; Nolla, J. M.; Keay, S. J.; TARRÚs, J., 1988: La vil.la romana de Vilauba (Camós). Serie Monográfica, 8, C.I.A.G., Gerona.

TED'A, 1989: Un abocador del segle $V$ d.C. en el Fòrum provincial de Tarraco, Memòries d'excavació, 2, Tarragona.

Tortorella, S., 1980: La sigillata africana a Cartagine fra il 400 d.C. e la conquista vandala: idati dello scavo della missione archeologica italiana, La céramique antique de Carthage. CEDHAC Carthage Dossiers L. Cartago, 125-139.

Whitehouse, D.; Barker, G.; Reele, R.; Reese, D., 1982: The Schola Praeconum I: The Coins, Pottery, Lamps and Fauna, Papers of the British School at Rome, L, 53-101. 